

\title{
CURRENCY SPILLOVERS AND TRI-POLARITY: A SIMULTANEOUS MODEL OF THE US DOLLAR, GERMAN MARK AND JAPANESE YEN
}

\author{
Ronald MacDonald ${ }^{a^{*}}$ and Ian W. Marsh ${ }^{\mathrm{b}}$ \\ June, 1999
}

\begin{abstract}
This paper presents a simultaneous model of exchange rates between the three major countries. In addition to incorporating long-run equilibria and short-run dynamics, the model is designed to capture complex interactions between currencies not normally considered in exchange rate models. These interactions are shown to be important via generalised impulse response analysis, and the model as a whole to be an economically and statistically superior forecasting tool over relatively short horizons.
\end{abstract}

\section{JEL Code: F31}

Keywords: Exchange rates, spillovers, forecasting, PPP, impulse response OLN. Tel 44141552 4400, email r.r.macdonald@strath.ac.uk London EC2Y 4HB, and CEPR. Tel 44171477 8609, email i.marsh@city.ac.uk Corresponding author. 


\section{NON-TECHNICAL SUMMARY}

The advent of the euro means that the international monetary system will effectively be characterised by a tri-polar currency structure, consisting of the US dollar, Japanese yen and euro. Recently, there has been considerable interest in policy circles regarding the operation and design of this system. Should it be a freely floating system, a managed float (based perhaps on a target zone arrangement) or one of complete fixity? In this paper we seek to shed some light on the operation of the new system by considering a tri-polar exchange rate model consisting of the US dollar, Japanese yen and German mark, which may be regarded as the antecedent to the new system. Because of the different operational objectives of the European Central Bank relative to the Bundesbank, the euro may, of course, have different properties to the mark. Nevertheless, we believe that the study of the dollar-mark-yen system is useful both in terms of indicating how a tri-polar network may be modelled, and also in suggesting how such a system may behave in terms of its long- and short-run properties.

Long-run purchasing power parity (PPP) forms the basis of our modelling exercise. While there is now general agreement that PPP does not hold in the short-run, except for cases of (near) hyperinflation, as a long-run proposition the evidence is much more favourable. Still, the fact that the majority of empirical papers on PPP reject the restrictions of proportionality and symmetry is rather worrying for a PPP-based study. This divergence from the theoretical value is sufficiently large for us to conclude that something more than measurement errors is at hand, and in line with Cassel's synthesis of PPP and asset demand approaches to the exchange rate, we shall augment the traditional PPP relationship.

The particular approach used here to augment PPP entails supplementing the PPP relationship with an interest differential. This augmentation of the basic PPP model is motivated through the balance of payments equilibrium condition under which the current and capital accounts sum to zero. Although this kind of representation of the equilibrium exchange rate may be unfashionable from the perspective of open economy macro-models, from an empirical perspective, and especially for a period such as the recent float, it seems unreasonable to force stock-flow equilibrium, particularly with respect to long-term capital movements.

One of the deficiencies of many fundamentals-based models is that they often neglect the dynamics inherent in the exchange rate process. To the extent that exchange rate models do incorporate dynamics, they are often very limited in scope. The econometric methods proposed here ensure a very rich dynamic specification for the exchange rate relationship, and also for the equations of the other fundamental variables driving the exchange rate.

In addition to having a complex dynamic structure, the tri-polar model analysed here is particularly designed to capture spillovers between foreign exchange markets. Although such spillovers are not typically modelled in the academic literature, it seems a natural component of an exchange rate model since it is widely accepted that currency markets are not independent. One of the main contributions of this paper then is the emphasis laid on the complex interactions among the variables in an exchange rate system. 
The importance of such interactions is assessed by subjecting the model to a range of shocks characteristic of the recent float. The dynamic responses of each variable in the system can then be graphed, often revealing long and complex lags in the adjustment process, and transmission of disequilibrium around the system.

The model is also assessed using standard statistical criteria and also by what has become the benchmark by which an exchange rate model is judged, namely its ability to predict exchange rate movements in an out-of-sample forecasting exercise. The model fares well, statistically out-performing the standard benchmark models at all forecast horizons in excess of two months for the yen, and five months for the mark.

Given the current interest in academic and policy circles in the behaviour of the tri-polar relationship between the euro, dollar and yen, we believe our results are suggestive of the functioning of such a system. Our approach suggests, for example, that such a system will exhibit both long- and short-run predictability (and the interaction amongst variables accords with economic intuition) and this may be useful from the perspective of setting target zone bands and monitoring their evolution over time. Furthermore, our analysis suggests that shocks to the system, originating in the system itself, do not create excess exchange rate volatility. This in turn may give comfort to those who favour a freely floating structure for the tri-polar grouping since it seems to imply that the system will be more stable than a system based on multiple bilateral relationships. 


\section{Introduction}

The advent of the Euro means that the international monetary system will effectively be characterised by a tri-polar currency structure, consisting of the US dollar, Japanese yen and euro. Recently, there has been considerable interest in policy circles regarding the operation and design of this system. Should it be a freely floating system, a managed float (based perhaps on a target zone arrangement) or one of complete fixity? In this paper we seek to shed some light on the operation of the new system by considering a tri-polar exchange rate model consisting of the US dollar, Japanese yen and German mark, which may be regarded as the antecedent to the new system. Because of the different operational objectives of the European Central Bank relative to the Bundesbank, the euro may, of course, have different properties to the mark. Nevertheless, we believe that the study of the dollar-mark-yen system is useful both in terms of indicating how a tri-polar network may be modelled, and also in suggesting how such a system may behave in terms of its long- and short-run properties.

Our tri-polar exchange rate system represents an extension of the joint modelling of exchange rates, interest rates and prices by Johansen and Jueslius (1995), Juselius (1995) and MacDonald and Marsh $(1997,1999)$. The latter authors, for example, used structural econometric techniques to estimate fully simultaneous exchange rate models for the US bilateral exchange rates of the German mark, Japanese yen and UK pound. These models were shown to have very good out-of-sample forecasting properties, compared to a simple random walk model, and also relative to a panel of professional forecasters. However, the approach of MacDonald and Marsh may be improved in several ways. First, their modelling exercise produced excess cointegrating vectors, some of which were difficult to interpret economically. Secondly, some of the coefficient signs, particularly those on interest rates, were incorrect in terms of the underlying economic model. The tri-polar model analysed here overcomes these shortcomings by capturing spillovers between foreign exchange markets. Although such spillovers have not to our knowledge been modelled in the academic literature (other than by accounting for contemporaneous correlation between exchange markets), it seems a natural component of an exchange rate model since it is widely accepted that currency markets are not independent.

One of the main contributions of this paper is the emphasis laid on the complex dynamic interactions among the variables in an exchange rate system. One of the deficiencies of many fundamentals-based models is that they often neglect the dynamics inherent in the exchange rate process. To the extent that exchange rate models do incorporate dynamics, they are often very limited in scope. The econometric methods proposed here ensure a very rich dynamic specification for the exchange rate relationship and also for the equations of the other fundamental variables driving the exchange rate. We analyse the interactions amongst the dynamic processes using a generalised impulse response analysis. This produces shocks which are order free and based on a 'typical' or 'system wide' shock to the system. The GIR approach has the added advantage that it is relatively easy to impose any long-run cointegrating relationships on the model structure.

Our exchange rate model is assessed using standard statistical criteria and also by what has become the benchmark by which an exchange rate model is judged, namely its ability to outperform a random walk model in an out-of-sample forecasting exercise.

The outline of the remainder of this paper is as follows. In the next section we present a motivational discussion for the modelling approach adopted. In section 3 the econometric methods are briefly outlined. Section 4 is the results section and contains a discussion of the estimated long-run cointegration relationships and generalised impulse response functions. Finally, the paper contains a concluding section. 


\section{Motivation and related research.}

Long-run purchasing power parity (PPP) forms the basis of our modelling exercise. Since, in one form or another, it is an assumed condition for almost every model of the exchange rate, PPP has received a huge amount of attention in the academic literature. While there is now general agreement that PPP does not hold in the short-run, except for cases of (near) hyperinflation, as a long-run proposition the evidence is much more favourable. For example, single country studies which exploit the methods of Johansen and Phillips/Phillips-Hansen to test for cointegration between nominal exchange rates and relative prices find clear evidence of such long-run relationships for both US dollar and Deutschmark bilateral rates (see, inter alia, Cheung and Lai, 1993a; Kugler and Lenz, 1993; MacDonald, 1993; and MacDonald and Moore, 1996). For currency pairings involving the US dollar there is little evidence of homogeneity or symmetry holding, although this is much stronger for mark-based rates (see Froot and Rogoff, 1995; and MacDonald, 1995, for extensive surveys of the recent literature on purchasing power parity).

The fact that the majority of empirical papers on PPP reject the restrictions of proportionality and symmetry is rather worrying for a PPP-based study. It has been suggested that measurement errors might account for the rejection of proportionality, and indeed the question of which is the most appropriate index has been debated since PPP was developed (Patel, 1990). Experimentation with several different indices has not found any systematic difference between results, with the absolute price elasticities usually significantly greater than unity. This divergence from the theoretical value is sufficiently large for us to conclude that something more than measurement errors is at hand, and in line with Cassel's synthesis of PPP and asset demand approaches to the exchange rate, we shall augment the traditional PPP relationship (see Holmes, 1967, for further discussion).

Adopting PPP as a basis for our model also supports our choice of econometric approach. Frenkel (1981) argues that much of the controversy surrounding PPP stems from the fact that it is an equilibrium condition and does not provide any detail on which forces bring about such a relationship. If prices react to competitiveness changes imposed by shifts in the exchange rate, PPP becomes a theory of price setting rather than one of exchange rates. Therefore, Frenkel asserts, PPP should not be viewed as a theory of exchange rate determination. While this lack of a causal link may invalidate the use of PPP in single equation models, it bodes well for the systems-based approach used here. Since dynamic equations are specified for all variables in the system, the effect of goods arbitrage on the exchange rate, and pricing to market/competitiveness effects on price levels will be fully captured.

The particular approach used here to augment PPP is discussed in some detail in Johansen and Juselius (1995), Juselius (1995), and MacDonald and Marsh (1997) and essentially entails supplementing the PPP relationship with an interest differential. ${ }^{1}$ Since Gustav Cassel emphasised the role of capital flows in preventing an exchange rate from always being at its equilibrium value, MacDonald and Marsh have labelled this approach to exchange rate modelling as Casselian PPP. One simple way of motivating this augmentation of the basic PPP model is to consider the balance of payments equilibrium condition under which the current $(\mathrm{ca})$ and capital $(\mathrm{ka})$ accounts sum to zero. Assume that the long-run equilibrium current account is a function

\footnotetext{
${ }^{1}$ In Johansen and Juselius (1995) and Juselius (1995) capital is assumed to be perfectly mobile and so uncovered interest rate parity holds continuously. Here we assume capital, although highly mobile, is not perfectly elastic with respect to the expected interest differential. Apart from this difference, the two approaches are very similar.
} 
of competitiveness, while the capital account position depends on nominal interest differentials adjusted for expected exchange rate changes:

$$
c a_{t}+k a_{t}=\alpha\left(s_{t}-p_{t}+p_{t}^{*}\right)+\mu\left(i_{t}-i_{t}^{*}-\Delta s_{t+k}^{e}\right)=0,
$$

where $s$ is the $(\log )$ spot exchange rate, $p$ is the $(\log )$ price level, $i$ is the $k$ period interest rate. An asterisk denotes a foreign (US) variable, $\Delta$ is the difference operator and superscript $e$ denotes expectations such that $\Delta s_{t+k}^{e}$ represents the expected change in the exchange rate over the subsequent $k$ periods. The parameter $\alpha$ is the elasticity of net exports with respect to competitiveness, and $\mu$ captures the mobility of international capital.

Assuming that capital is less than perfectly mobile $(\mu<\infty)$ equation (1) may be solved for the exchange rate to give an equilibrium relationship which is relevant for our sample period:

$$
s_{t}=p_{t}-p_{t}^{*}-\gamma\left(i_{t}-i_{t}^{*}-\Delta s_{t+k}^{e}\right)+\xi_{t},
$$

where $\gamma$ equals $(\mu / \alpha)$ and $\xi$ is an error term which should be $I(0)$. MacDonald and Marsh label this expression Casselian PPP. Although this kind of representation of the equilibrium exchange rate may be unfashionable from the perspective of open economy macro-models, from an empirical perspective, and especially for a period such as the recent float, it seems unreasonable to force stock-flow equilibrium, particularly with respect to long-term capital movements. It may be that such non-zero capital account effects reflect productivity differentials, expected inflation differentials or the influence of relative monetary policies. Although these underlying factors are not explicitly modelled in this paper, we believe that they may have persistent effects on exchange rates.

An alternative, statistical, interpretation of (2) is that the potential non-stationarity of the real exchange rate, $\left(s-p+p^{*}\right) \sim I(1)$, is removed by the non-stationarity of the interest rate differential, $\left(i-i^{*}\right) \sim I(1)$. Juselius (1995) has suggested expressing this as:

$$
\left(\omega_{1}\left(i-i^{*}\right)-\omega_{2}\left(p-p^{*}\right)+s\right) \sim I(0),
$$

where the omegas enter to allow for the effects of temporal aggregation and the weak correspondence that may exist between theoretical and observed variables.

The empirical model sketched above is clearly not intended to be complete. However, the simplifications made do in fact allow us to address the common and important empirical finding of non-homogeneity of prices and to provide a firm foundation from which we can produce sensible exchange rate models.

Both Johansen and Juselius (1995), Juselius (1995) and MacDonald and Marsh $(1997,1999)$ use variants of the above model and find clear evidence of stationary. The main novelty in the present paper is to note that currency markets are closely linked and so any statistical analysis should explicitly recognise this. Since we analyse the US dollar bilateral exchange rates of the Japanese yen and German mark we propose analysing these markets jointly. In the context of the above model this amounts to analysing the following data vector:

$$
x=\left(s^{G E R}, s^{J A P}, p^{G E R}, p^{J A P}, p^{U S}, i^{G E R}, i^{J A P}, i^{U S}\right),
$$

where the superscripts GER, JAP and US represent Germany, Japan and the US, respectively. We then propose testing hypotheses on this vector which allow us to partition the long-run cointegrating space into two long-run stationary relationships of the form: 


$$
\begin{aligned}
\beta^{G E R} x & =\omega_{1}^{G E R}\left(i^{G E R}-i^{U S}\right)-\omega_{2}^{G E R}\left(p^{G E R}-p^{U S}\right)+S \\
\beta^{J A P} x & =\omega_{1}^{J A P}\left(i^{J A P}-i^{U S}\right)-\omega_{2}^{J A P}\left(p^{J A P}-p^{U S}\right)+S^{J A P} .
\end{aligned}
$$

Although there are not spillovers from one currency market to the other in these long-run relationships, there may nevertheless be information contained in the joint process from the two markets which is important in defining the long-run and would be ignored by simply conditioning on the information set from one market. However, direct spillovers do appear in the short-run dynamic equations. This may be seen in the following way. Engle and Granger (1987) have demonstrated that if cointegration exists amongst a group of variables then an error correction representation must exist for that group. In the current context this means that we have dynamic equations of the following form (where we have chosen the dynamic equation for the German mark, and $l$ represents the lag length of the differenced VAR):

$$
\begin{gathered}
E R=\gamma_{0}+\Sigma_{i=1}^{i=l} \gamma_{1 i} \Delta s_{t-i}^{G E R}+\sum_{i=1}^{i=l} \gamma_{2 i} \Delta s_{t-i}^{J A P}+\sum_{i=1}^{i=l} \gamma_{3 i} \Delta p_{t-i}^{G E R}+\Sigma_{i=1}^{i=l} \gamma_{4 i} \Delta p_{t-i}^{J A} \\
\Sigma_{i=1}^{i=l} \gamma_{5 i} \Delta p_{t-i}^{U S}+\Sigma_{i=1}^{i=l} \gamma_{6 i} \Delta i_{t-i}^{G E R}+\sum_{i=1}^{i=l} \gamma_{7 i} \Delta i_{t-i}^{J A P}+\Sigma_{i=1}^{i=l} \gamma_{8 i} \Delta i_{t-i}^{U S}+ \\
\alpha_{1} \beta^{G E R} x_{t-1}+\alpha_{2} \beta^{J A P} x_{t-1} .
\end{gathered}
$$

Hence spillovers arise both through dynamic interactions and also through the significance of the cointegrating relationships (the alphas). As we shall see in our empirical section, both of these effects are important.

\section{Econometric methods}

In this section we briefly outline the econometric methods used to estimate our exchange rate models. In short, we use a vector autoregressive model to determine the number of cointegrating relationships and to define the cointegrating vectors. This part of our analysis is based on the methods of Johansen (1995). The dynamic interactions amongst the variables in the systems are then examined using the generalised impulse response approach.

\subsection{Econometric modelling}

We assume a familiar VAR representation:

$$
x_{t}=\sum_{i=1}^{l+1} A_{i} x_{t-i}+\psi D_{t}+v_{t}
$$

which may be reparameterised into the VECM representation:

$$
\Delta x_{t}=\sum_{i=1}^{l} \Gamma_{i} \Delta x_{t-i}+\Pi x_{t-1}+\psi D_{t}+v_{t}
$$

where $\boldsymbol{x}$ is a vector of variables entering the system, $\boldsymbol{D}_{t}$ contains deterministic components (constant, trend, centred seasonal dummies and event dummies) and $\boldsymbol{v}_{t}$ is assumed to have mean zero, be homoscedastic and serially uncorrelated. The order of the VAR is assumed finite to exclude moving average components, and the parameters $\mathbf{A}_{i}, \boldsymbol{\Gamma}_{i}, \boldsymbol{\psi}$, and $\Sigma$ (the covariance matrix of $\boldsymbol{v}$ ) are assumed constant. $\boldsymbol{\Pi}$ is interpreted as the matrix of long-run responses. If the data cointegrate, $\boldsymbol{\Pi}$ must be of reduced rank, $r<N$, where $N$ is the number of variables in $\boldsymbol{x}$. It can be factored such that: 


$$
\Pi=\alpha \beta^{\prime},
$$

where $\beta$ and $\alpha$ are $p \times r$ matrices, which give the cointegrating vectors (empirical long-run relationships) and associated adjustment matrix, respectively (Johansen, 1988; Johansen and Juselius, 1990, 1992). Due to the reduced form nature of the cointegrating vectors there is an increasing trend towards performing transformations and imposing restrictions on the estimated cointegrating space to reveal 'meaningful economic relationships'.

The imposition of restrictions on the cointegrating vector or adjustment matrix will change the estimated short-run dynamics of equation (7) and the coefficients of the deterministic variables. These new coefficients are denoted by a tilde. If we also denote the restricted cointegration space by $\tilde{\Pi}=\tilde{\alpha} \tilde{\beta}^{\prime}$, the constrained VAR (CVAR) can be written as:

$$
\Delta x_{t}=\sum_{i=1}^{l} \tilde{\Gamma}_{i} \Delta x_{t-i}+\tilde{\Pi} x_{t-1}+\tilde{\psi} D_{t}+w_{t} .
$$

This is the full vector form of the dynamic equation (5) above, with additional deterministic components included.

\subsection{Generalised impulse response analysis}

The standard way of judging the interaction of variables in a relatively large cointegrated system is to conduct impulse response analysis (Lütkepohl and Reimers, 1992). Typically in such analysis the cointegrated VAR is subjected to an orthogonalised shock in one variable and the response of the system is examined. This response is implicitly compared to a baseline where no shock is present. Unfortunately, such analysis is plagued by problems due to the dependence of results on the ordering of the variables used to obtain the orthogonal shocks. In our system, in particular, the presence of five asset prices makes analysis based on the imposition of one individual a priori ordering very suspect.

Recent research has re-examined the concept of impulse response analysis with the aim of removing this shortcoming (Koop, Pesaran and Potter, 1996; Pesaran and Shin, 1998). Instead of using orthogonalised shocks from a Cholesky decomposition, these generalised impulse responses (GIRs) are based on a "typical" shock to the system. The average response of the system to this typical shock is compared to the average baseline model absent the shock (see Agénor, Hoffmaister and Medeiros, 1997, for more details). Rather than examining the effect of a pure shock to, say, the US interest rate, GIR analysis considers a typical historical innovation which embodies information on the contemporaneous correlation between innovations.

Consider the $m$-variable CVAR model written in an infinite moving average form:

$$
\Delta x_{t}=\mu+\sum_{i=0}^{\infty} C_{i} \varepsilon_{t-i}
$$

where $\mu$ is an $(m \times 1)$ vector of constants and $\varepsilon_{t}$ are unobserved vectors of "shocks" which are jointly normally distributed, of zero mean and has a constant variance-covariance matrix $\Omega$ with typical element $\sigma_{i, j}$. Then

$$
E\left[\varepsilon_{t} \mid \varepsilon_{j t}=\varepsilon_{j t}^{0}\right]=\sigma_{j j}^{-1} \varepsilon_{j t}^{0} \Omega e_{j}
$$

where $e_{j}$ is an $(m \times 1)$ selection vector with element $j$ equal to unity and zeros elsewhere. Then the GIRs of the effect of a shock to the $j$ th disturbance term at time $t$ on $\Delta x_{t+n}$ are 


$$
\operatorname{GIR}_{\Delta x}(n, j)=\frac{C_{n} \Omega e_{j}}{\sqrt{\sigma_{j j}}} .
$$

and the GIRs of the $\boldsymbol{x}_{t^{+n}}$ following a "unit" shock to the $j$ th variable are

$$
\operatorname{GIR}_{x_{k}}(n, j)=\frac{B_{n} \Omega e_{j}}{\sqrt{\sigma_{j j}}}
$$

where $B_{n}=\sum_{m=0}^{n} C_{m}$ and the GIRs are measured $n$ periods after the shock occurs. Writing the cointegrating vectors as

$$
z_{t}=\beta^{\prime} x_{t}
$$

it is clear that the GIRs of $z_{t}$ with respect to a shock to the $j$ th equation are

$$
\operatorname{GIR}_{z_{t}}(n, j)=\frac{\beta^{\prime} B_{n} \Omega e_{j}}{\sqrt{\sigma_{j j}}} .
$$

The GIRs will only be numerically equivalent to the standard impulse response function based on Cholesky decompositions if $\Omega$ is diagonal. However, the GIR for the $j$ th shock will be equal to the standard impulse response when the $j$ th variable is put first in the ordering, which allows the GIR to be easily estimated in standard econometric packages.

\section{A tri-polar system of exchange rates}

In our empirical application of the model discussed in Section 2 we use short-term (three month) eurocurrency interest rates rather than long-term bond yields. There are two justifications for this. First, short-term rates have been used successfully by other authors who exploit similar systems (Fisher, et al. 1990; Johansen and Juselius, 1992; Lee, Pesaran and Shin, 1994). Second, factors such as taxation, duration and liquidity effects can cause bond yields to differ from the pure interest rate which we would like to observe. These factors are not only less prevalent in the short-term euromarkets, but are also more similar between currencies leading to, we hope, a better proxy for capital flows. The (log) of the spot exchange rate (national currency units per US dollar) and interest differentials (country minus US value) are given in figures 1 and 2 . Figure 1 also presents the ratio of German to US consumer price indices.

Consumer prices are our preferred price measure for Germany and the US, while for Japan we use the wholesale price index, maintaining consumer indices for the other countries. This change is motivated primarily on the marked differences in behaviour of the Japanese consumer and wholesale price indices. In many countries these proxies for 'the' price level follow similar trends. For Japan over the period studied they do not (figure 3), and our use of the wholesale index produced results which were more in conformity with the basic model.

\subsection{Long-run equilibria in the tri-polar system}

The eight variable system comprises two bilateral exchange rates (dollar-mark and dollar-yen), three price indices and three short-term interest rates. The expected exchange rate changes are not included in the vector of variables as these will be $I(0)$ under the weakest assumptions of 
rationality. The data run from January 1983 through December $1997 .^{2}$ The start date for estimation is set to exclude turbulence in the interest rate markets in the early 1980s caused by changes in the Federal Reserves' operating procedures, and which necessitated the use of many intervention dummies in previous work (see MacDonald and Marsh, 1997). Just two dummies are needed in this system (1985:11 and 1986:01), primarily to remove two outliers in the Japanese interest rate series. Four lagged levels in the VAR, chosen after performing a battery of tests, and centred seasonal dummies are included in the system. Some of the tests indicated a shorter system but we chose to include the maximum amount of relevant information albeit at the possible cost of estimation accuracy.

In Table 1 we report some diagnostics from our estimated VAR models. The portmanteau $L M(1)$ and $L M(4)$ tests indicate that the residuals are random, although the $N M$ portmanteau test of non-normality indicates normality problems in our system. Reassuringly this is due to kurtosis, rather than skewness. Incorporating further dummy variables into the VAR models proved unsuccessful in removing this kurtosis. In Figures A1 to A8 we report plots of the actual and fitted values of all the series, along with the associated standardised residuals, histograms and correlograms. We interpret these figures as indicating that our joint model is statistically well founded.

As we noted in Section 2, the long-term equilibria are of the following form:

$$
\begin{gathered}
s_{t}^{G E R}=p_{t}^{G E R}-p_{t}^{U S}-\omega_{1}^{G E R}\left(i_{t}^{G E R}-i_{t}^{U S}\right)+\xi_{t}^{G E R}, \\
s_{t}^{J A P}=p_{t}^{J A P}-p_{t}^{U S}-\omega_{1}^{J A P}\left(i_{t}^{J A P}-i_{t}^{U S}\right)+\xi_{t}^{J A P},
\end{gathered}
$$

where $i$ denotes a short-term, three month euro-interest rate. The Johansen cointegration test results are detailed in Table 2. The more reliable trace test (Cheung and Lai, 1993b) indicates two significant relationships, and this is supported by the presence of two noticeably larger eigenvectors. The unrestricted relationships bear little resemblance to the hypothesized relationships.

The testable restrictions implied by the theory and imposed on the model are summarized in Table 3. The results of imposing these restrictions are also detailed in Table 3. Simple PPP (with symmetry and proportionality imposed) is rejected for both exchange rates. Casselian PPP cannot be rejected for either exchange rate, and the tests would seem to indicate that PPP augmented by the relevant interest differential is an acceptable description of both cointegrating relationships (hypothesis B3).

The final restricted cointegrating vectors are as follows:

$$
\begin{gathered}
C V_{1}=s_{t}^{G E R}-p_{t}^{G E R}+p_{t}^{U S}+0.132\left(i_{t}^{G E R}-i_{t}^{U S}\right) \\
C V_{2}=s_{t}^{J A P}-p_{t}^{J A P}+p_{t}^{U S}+0.318\left(i_{t}^{J A P}-i_{t}^{U S}\right)
\end{gathered}
$$

\footnotetext{
2 These data are extracted from the IMF's International Financial Statistics CD Rom.
} 
These vectors closely accord with the theory outlined in section 2 . The vectors are plotted in Figures A9 and A10, where the top graph shows the actual disequilibrium as a function of all short -run dynamics, including the seasonals and event dummies, while the series in the bottom half is the disequilibrium purged of the short-run dynamics. These figures confirm our choice of two cointegrating relationships. Additionally, the similarity between the relationships in the top and bottom graphs in each of A9 and A10 indicates that our data vector is first order nonstationary (see Hansen and Juselius, 1994). However, since Juselius (1995) has noted that in macro systems featuring prices (and money) there may exist $I(2)$ trends we decided to explore this issue further.

An $I(2)$ system can be decomposed into $I(0), I(1)$ and $I(2)$ directions, with dimensions $r, s_{1}$ and $p-r-s_{1}=s_{2}$, respectively. Since $I(1)$ and $I(2)$ systems imply different numbers of unit roots for the characteristic polynomial, an analysis of the roots can be informative when assessing the orders of integration of the system. We therefore calculated the eigenvalues of the companion matrix (the 'A' matrix in (6)) and the $p \times k=32$ roots are shown in Figure A11. The first five roots are all approximately 0.98 or greater. There are then a pair of complex roots having a modulus of 0.88 and the eighth root has a value of 0.82 . These results are therefore not very helpful in determining if there are indeed $I(2)$ trends in our system. We therefore followed the $I(2)$ testing method proposed by Johansen and explicitly tested for I(2)-ness in our restricted model using the Pantula principle and the significance levels of Paruolo (1995). No evidence of $I(2)$ trends was found. We therefore proceed on the basis of the results from the $I(1)$ model.

The loadings matrix associated with the two cointegrating vectors shows the importance of the tri-polar nature of the system (Table 4). In particular, the fact that German interest rates, and to a lesser extent US prices, significantly adjust to remove disequilibrium in both cointegrating vectors implies that disturbances will be transmitted around the whole system, even if a shock occurs to just one leg. For example, if there is a shock to Japanese prices which pushes $\mathrm{CV}_{2}$ out of equilibrium, not only will Japanese variables act to restore equilibrium, but so will US prices and even German interest rates. Since both of these latter terms help to form $\mathrm{CV}_{1}$, disequilibrium spills from one exchange rate to another. This seems to confirm the conventional wisdom about how foreign exchange markets work, although it has not to our knowledge been demonstrated formally before. The system-wide reaction to shocks is examined in more detail in the next sub-section using a generalised impulse response analysis.

\subsection{Generalised impulse response analysis of the tri-polar system}

What does the dynamic interaction amongst the variables in our systems look like? This question is clearly of considerable practical interest given that the current construction of the international monetary system is effectively tri-polar. To answer this question we computed generalised impulse responses for our system of eight variables and two restricted cointegrating vectors. Again they show the importance of modelling these three countries as a system as impulses in, say, Japanese interest rates tend to be associated with impulses to German rates. Furthermore, as we shall see, innovations are clearly transmitted around the whole system. Estimating the bilateral models separately would lose this potentially important information. A selection of generalised impulse responses are shown in Figures 4 to 6. 
In Figure 4 we show the system-wide effects of a one standard deviation shock to US prices. The generalised nature of these impulse responses is apparent from the simultaneous behaviour of the other price series - typically, a positive shock to US prices is associated with positive shocks to Japanese and German prices, with the former at least perturbed by a similar magnitude. It is noticeable that the US price level reaches equilibrium much faster than the two other price levels. Even so, the long-run effects are essentially identical across all three price levels. Rising prices also typically elicit rising short-term interest rates. The cumulated responses indicate that interest rates continue to rise for several months, but are virtually unaffected in the long-run. This is perhaps what we would expect from a traditional Fisherian view of interest rate determination: in a world of rising prices interest rates should match the inflation on a one-to-one basis, but as long as the price/inflation change is transitory it will not have a long-run effect.

Finally, we note the immediate depreciation of the currencies, followed by prolonged adjustments in the exchange rates as (non-US) prices and (all) interest rates continue to adjust to the shock. The cumulated exchange rate responses show a short-term depreciation (over approximately 24 months) followed by a longer-run appreciation for both currencies against the dollar. This shock, common to both cointegrating vectors, produces similar long-term effects on all three countries, although the paths of prices, in particular, differ across countries.

Figure 5 gives similar plots for a one standard deviation shock to the German price level. Even although this is a shock to just one of the cointegrating vectors it is noticeable that the longrun effects are very similar for both German and Japanese variables - price levels rise (but not in the US), interest rates fall eventually, and by a similar magnitude, and both the mark and yen depreciate against the dollar, again by similar magnitudes. We see similar adjustment paths for prices from both of these shocks. Japanese and US prices over-react with US prices adjusting much more rapidly, while German price adjustments are positively correlated.

Finally in this sub-section we present the generalised impulse responses from a shock to the level of Japanese euro interest rates (figure 6). A one standard deviation (17 basis point) increase in Japanese rates is associated with a contemporaneous $3 \mathrm{bp}$ and $4 \mathrm{bp}$ rise in US and German rates, small jumps in world-wide price levels, and initially a drop in the value of the mark and yen. Interest rates continue to rise in the medium-term, but in the longer-run Japanese interest rates return to their pre-shock level, German rates rise by $7.5 \mathrm{bp}$ and US interest rates fall by $9 \mathrm{bp}$. There is an asymmetric long-run response by prices - US and German prices rise by similar amounts (again following their characteristic patterns), while Japanese prices fall - and both the mark and yen appreciate in the long-term despite initial depreciations.

Figure 7 shows the generalised impulse responses of the two equilibrium terms to the Japanese interest rate shock. These shocks are useful since although shocks on individual variables in a VAR may exhibit considerable persistence, shocks to the cointegrating vectors must die out. In this sense this figure should give useful information on the speed of adjustment of the model to its equilibrium relationships. The Japanese cointegrating term decays steadily from its initial high point, but still has not totally reached equilibrium after one hundred periods. The German cointegrating vector, only indirectly affected in the initial period by the contemporaneous nature of GIR shocks, swings from positive, to negative and back again. The 
maximal effect is felt after thirty periods before it too slowly decays towards equilibrium. The implied half-lives for this shock are approximately six years for the Japanese cointegration terms and about four years in the case of the German relationship. These numbers are in the ball park of half-lives derived from PPP-based studies which use long time spans of data, but of course are derived for the recent floating period (and are therefore much faster than other estimated halflives for this period). To further improve these adjustment speeds would probably require conditioning on other information which more closely tracks the evolution of the real exchange rate (such as net foreign asset accumulation or productivity differences).

\subsection{Forecasting accuracy}

While the equilibrium estimates for the tri-polar model look plausible and the impulse response analysis shows interesting results, ever since Meese and Rogoff(1983) the real test of the validity of an exchange rate model lies in its forecasting power.

The above analysis has been performed on the system estimated over the full data-span. To allow the computation of out-of-sample forecasts the entire model was re-estimated over the period 1983:01 to 1995:12. The long-run cointegrating relationships were re-imposed, namely PPP augmented by interest differentials, but the coefficients on the interest differentials were reestimated. Out-of-sample forecasts for one to twelve months ahead were then made. One observation was then added to the end of the sample and the entire process repeated, including estimation of the model. The final estimation is for the period 1983:01 to 1997:12. The free coefficients in the cointegrating relationships and the short-run dynamics were therefore allowed to change over time.

The coefficients in the cointegrating relationship are graphed in Figure 8. The coefficient on the interest differential in the German relationship varies between 0.097-0.132, while the coefficient on the Japanese differential in the second vector lies in the range $0.123-0.318$. The relative stability of the German vector strengthens our belief that we have captured a meaningful relationship. However, the movements in the Japanese coefficient may indicate that we are excluding an important variable from our simple model, and we question the appropriateness of (short-term) interest rates as a proxy for capital flows in the Japanese case. Further refinements of the model might usefully employ some measure of stock market performance which may be qualitatively more important for Japanese capital flows.

As in the original Meese and Rogoff study, and in many articles since, we take the driftless random walk as the benchmark against which we judge our model. The forecast performance is detailed in Table 5. For each horizon it gives the ratio of the RMSE of the model's exchange rate forecasts to those from a random walk model, the proportion of correct directional forecasts, and the RMSE ratio of a VAR set up in differences but with no cointegrating vectors. The root mean squared error is defined as

$$
R M S E=\sqrt{\frac{\sum_{t}\left(F_{t}-A_{t}\right)^{2}}{n}}
$$


where $F$ represents the forecast $(\log )$ level of the exchange rate, $A$ the actual outcome $(\log )$ exchange rate, and $n$ is the number of forecasts.

Good performance would be indicated by an RMSE ratio less than unity and directional ability in excess of $50 \%$. The significance of the relative forecast accuracy of the model compared to that of the random walk alternative is tested using the Diebold-Mariano (1995) procedure. Denote the model and random walk forecasts of the outcome spot rate, $A$, by $F_{\mathrm{M}}$ and $F_{\mathrm{RW}}$, respectively. Defining $e_{M}^{2}=\left(F_{M}-A\right)^{2}, e_{R W}^{2}=\left(F_{R W}-A\right)^{2}$, and $d=e_{M}^{2}-e_{R W}^{2}$, the DieboldMariano test is a $t$-test of the null that the mean of $d$ is zero, corrected for serial correlation induced by overlapping forecasts and heteroscedasticity where appropriate.

The results are clearly impressive. For the Deutschemark, the forecasts from the tri-polar model are both more accurate than the random walk and more likely to correctly suggest the direction of change than chance would suggest at all forecast horizons. The relative accuracy becomes statistically significant at the five-month forecast horizon. The yen forecasts become significantly more accurate than the random walk at the three-month horizon. In terms of directional forecast ability, the yen forecasts again prove better than pure chance would suggest at all horizons over one-month. Without seeking to denigrate the results, we would point out that over the longer forecast intervals, the yen consistently depreciated over the forecast period which explains the exceptional directional ability shown by the model from the eight-month forecast horizon. However, the model can only be asked to forecast reality, and we feel that the impressive predictions of the more volatile German unit validate its performance.

The RMSE ratios for the differenced VAR (i.e. no cointegrating relationships) is clearly inferior to both the VECM formulation and a random walk. The importance of including the cointegrating vectors is made apparent by this forecasting exercise.

\section{Conclusions}

In this paper we have sought to model the mark, dollar and yen using a simultaneous tripolar structure, which allows for spillovers between the currencies. The modelling strategy may be judged successful since we produced an interpretable exchange rate model with desirable economic properties. Most significantly, perhaps, when confronted with what is taken to be the most severe test of an exchange rate model - its out-of-sample forecasting ability - the model is capable of producing predictions which compare extremely well to two industry standard benchmarks. This performance is statistically significant and, we should add, of practical relevance - forecasts from models closely related to those presented here are currently used by corporate entities as part of their financial decision-making processes.

Given the current interest in academic and policy circles in the behaviour of the tri-polar relationship between the euro, dollar and yen, we believe our results are suggestive of the functioning of such a system. Our approach suggests, for example, that such a system will exhibit both long- and short-run predictability (and the interaction amongst variables accords with economic intuition) and this may be useful from the perspective of setting target zone bands and monitoring their evolution over time. Furthermore, our analysis suggests that shocks to the system, originating in the system itself, do not create excess exchange rate volatility. This in turn 
may give comfort to those who favour a freely floating structure for the tri-polar grouping since it seems to imply that the system will be more stable than a system based on multiple bilateral relationships.

There are a number of possible extensions of our modelling strategy. Most obviously, a more complete model of the determinants of exchange rates could be examined within a similar framework. Since it has already performed well in a single-equation setting (see, for example, MacDonald and Taylor, 1993) a prime candidate would be the monetary approach to the exchange rate. As a longer time series of data from the current float becomes available, expanding the system to include the increased number of variables such an approach requires should become less problematic.

Second, while the long-run equilibria are reasonably tightly specified in our model, shortrun dynamics are fully data-determined. Perhaps the rapidly expanding market-microstructure literature (see Frankel and Rose, 1995, for an overview) may one day give more concrete models on developments at a higher frequency. Since they are jointly determined both in reality and in most estimation techniques, combining the existing longer-run equilibria with more meaningful models of the short-run should enhance performance at both horizons. 


\section{References}

Agénor, P-R., A.W. Hoffmaister and C.I. Medeiros (1997) “Cyclical fluctuations in Brazil's real exchange rate: the role of domestic and external factors," International Monetary Fund Working Paper, WP/97/128.

Cheung, Y-W. and K.S. Lai (1993a) "Long-run purchasing power parity during the recent float," Journal of International Economics, Vol. 34, 181-192.

Cheung, Y-W. and K.S. Lai (1993b) "Finite-sample sizes of Johansen's likelihood ratio tests for cointegration," Oxford Bulletin of Economics and Statistics, Vol. 55, 313-328.

Diebold, F.X. and R.S. Mariano (1995) "Comparing predictive ability," Journal of Business and Economic Statistics, Vol. 13, 253-263.

Engel, R.F. and C.W.J. Granger (1987) "Co-integration and error correction: representation, estimation, and testing," Econometrica, Vol. 55, 251-76.

Fisher, P.G., S.K. Tanna, D.S. Turner, K.F. Wallis and J.D. Whitley (1990) "Econometric evaluation of the exchange rate in models of the UK economy," Economic Journal, Vol. $100,1230-1244$.

Frankel, J. and A. Rose (1995), "A Survey of Empirical Research on Nominal Exchange Rates" in E. Grossman and K. Rogoff(eds), The Handbook of International Economics, Vol. 3, Amsterdam: North Holland.

Frenkel, J.A. (1981) "Flexible exchange rates, prices and the role of 'news',"Journal of Political Economy, Vol. 89, 665-705.

Froot, Kenneth A., and Kenneth Rogoff, (1995) "Perspectives on PPP and Long-Run Real Exchange Rates", in Handbook of International Economics, Vol. 3, ed. by Ronald W. Jones and Peter B. Kenen (Amsterdam: North Holland).

Hansen, B. and K Juselius (1994), Manual to Cointegration Analysis of Time Series CATS in RATS, Institute of Economics, University of Copenhagen.

Holmes, J.M. (1967) "The purchasing power parity theory: in defence of Gustav Cassel as a modern theorist," Journal of Political Economy, Vol. 75, 686-695.

Johansen, S. (1988) "Statistical analysis of cointegration vectors," Journal of Economic Dynamics and Control, Vol. 12, 231-254.

Johansen, S. (1995), Likelihood-based Inference in Cointegrated Vector Autoregressive Models, Oxford: Oxford University Press.

Johansen, S. and K. Juselius (1990) "Maximum likelihood estimation and inference on cointegration - with applications to the demand for money," Oxford Bulletin of Economics and Statistics, Vol. 55, 169-210.

Johansen, S. and K. Juselius (1992) "Testing structural hypotheses in a multivariate cointegration analysis of the PPP and UIP for UK," Journal of Econometrics, Vol. 53, 211-244.

Johansen, S and K. Juselius (1992), "Testing structural hypothesis in a multivariate cointegration analysis of the PPP and the UIP for the UK", Journal of Econometrics, Vol. 53, 211-244.

Juselius, K. (1995), "Do purchasing power parity and uncovered interest rate parity hold in the long-run? An example of likelihood inference in a multivariate time series model", Journal of Econometrics, Vol. 69, 211-40. 
Koop, G., M.H. Pesaran and S.M. Potter (1996) "Impulse response analysis in nonlinear multivariate models," Journal of Econometrics, Vol. 74, 119-147.

Kugler, P. and C. Lenz (1993) "Multivariate cointegration analysis and the long-run validity of PPP," Review of Economics and Statistics, Vol. 75, 180-187.

Lee, K., M.H. Pesaran and Y. Shin (1994) "Exchange rate, price and interest rate dynamics in the UK: an application of the generalised impulse response analysis," mimeo, University of Cambridge.

Lütkepohl, H. and H.E. Reimers (1992) "Impulse response analysis of cointegrated systems," Journal of Economic Dynamics and Control, Vol. 16, 53-78.

MacDonald, R. (1993) “Long-run purchasing power parity: is it for real?" Review of Economics and Statistics, Vol. 75, 180-187.

MacDonald, R. (1995) “Long-run exchange rate modeling," International Monetary Fund Staff Papers, Vol. 42, 437-489.

MacDonald, R. and I.W. Marsh (1997) "On fundamentals and exchange rates: a Casselian perspective," Review of Economics and Statistics, Vol. 79, 655-664.

MacDonald, R. and I.W. Marsh (1999) Exchange Rate Modelling, Kluwer: Dordrecht.

MacDonald, R., and M. Moore, (1996) "Long-run purchasing power parity and structural change" Economie Appliquee, XLIX, 11-48.

MacDonald, R. and M.P. Taylor (1993) "The monetary approach to the exchange rate," International Monetary Fund Staff Papers, Vol. 40, 89-107.

Meese, R. and K. Rogoff (1983) "Empirical exchange rate models of the seventies: do they fit out of sample?" Journal of International Economics, Vol. 14, 3-24.

Paruolo, P. (1995), "On the determination of integration indices in I(2) systems", Journal of Econometrics, Vol. 72, 313-356.

Patel, J. (1990) "Purchasing power parity as a long-run relation," Journal of Applied Econometrics, Vol. 5, 367-379.

Pesaran, M.H. and Y. Shin (1998) "Generalized impulse response analysis in linear multivariate models," Economics Letters, Vol. 58, 17-29. 
Figure 1

German data

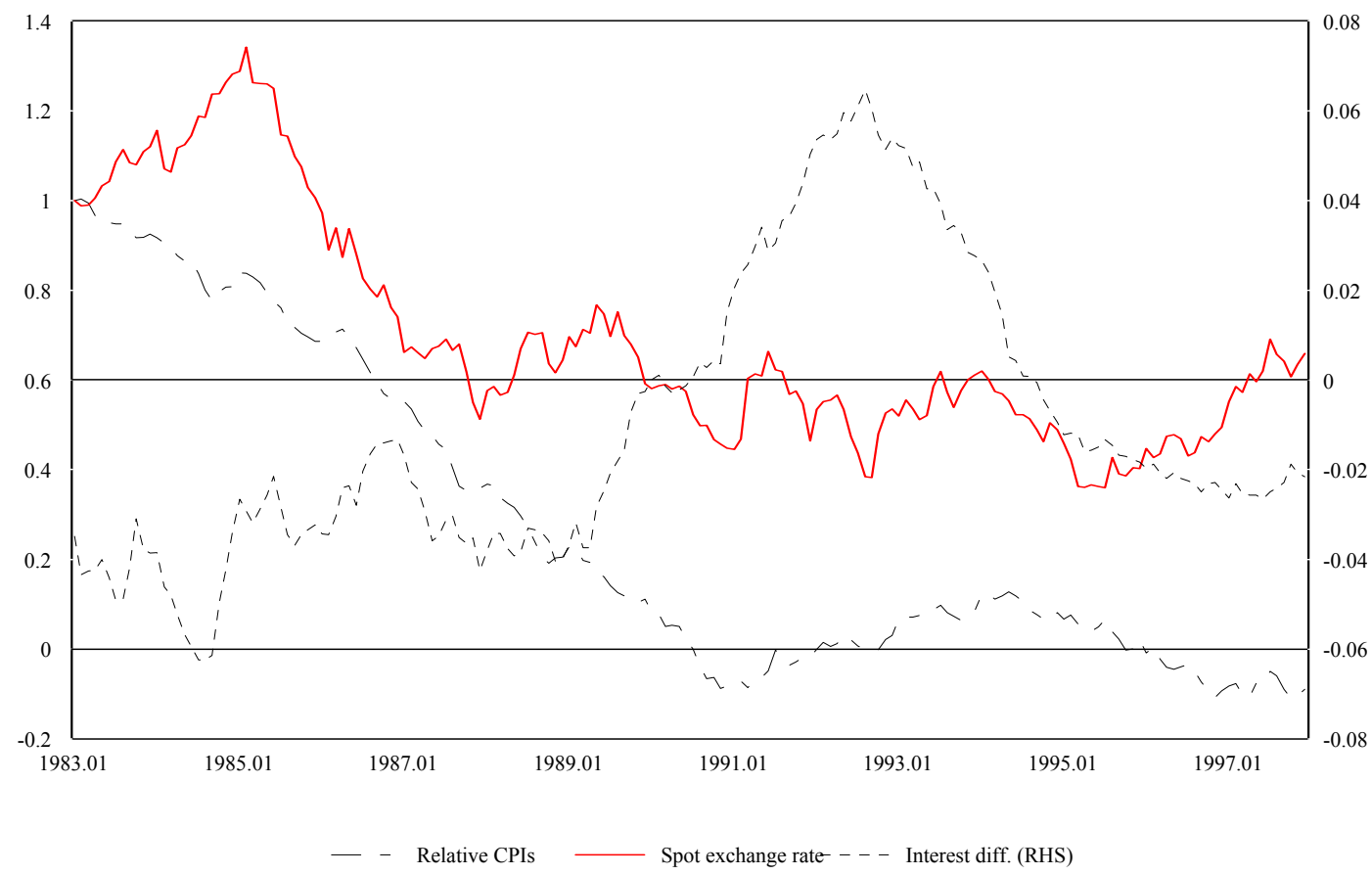


Figure 2

Japanese exchange and interest rate data

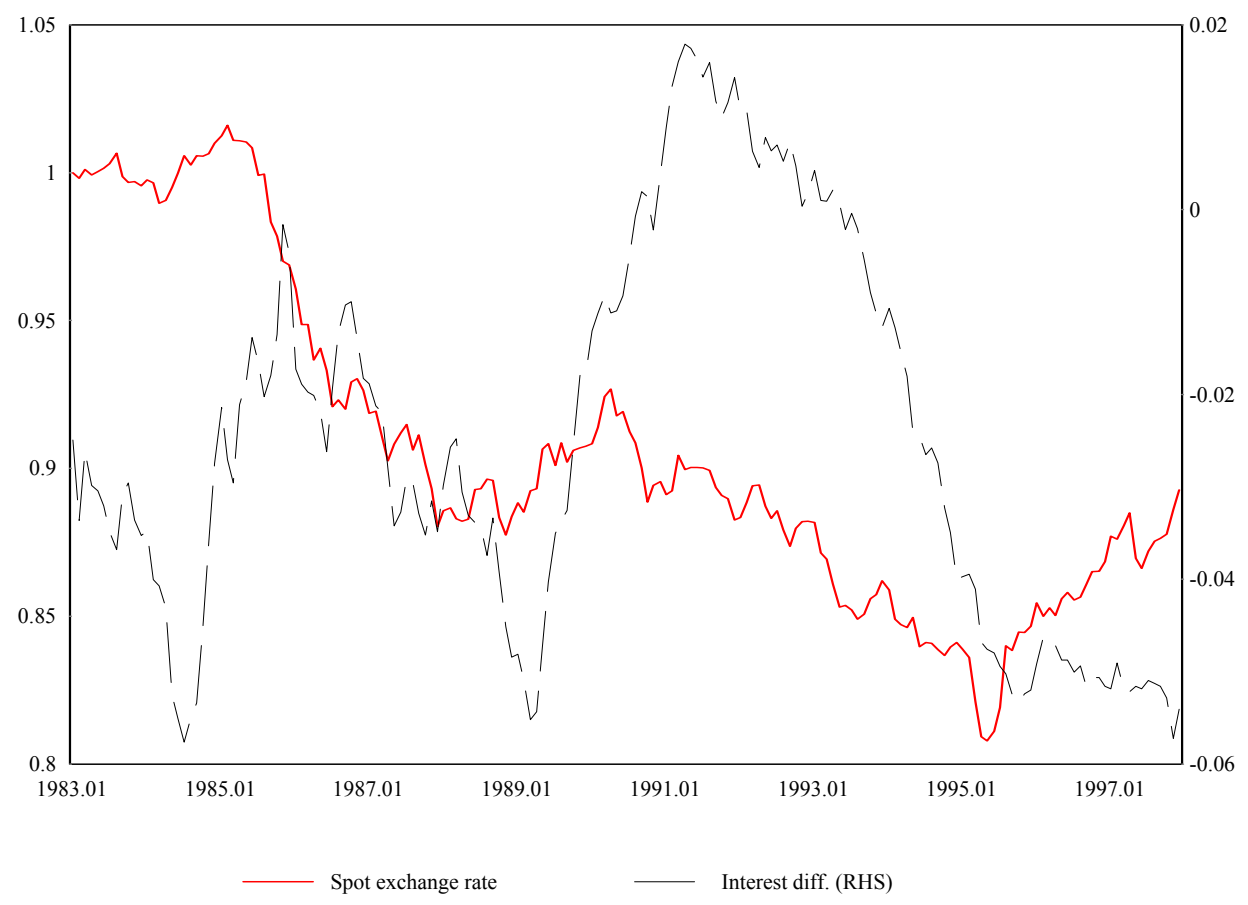


Figure 3

Japanese price indices

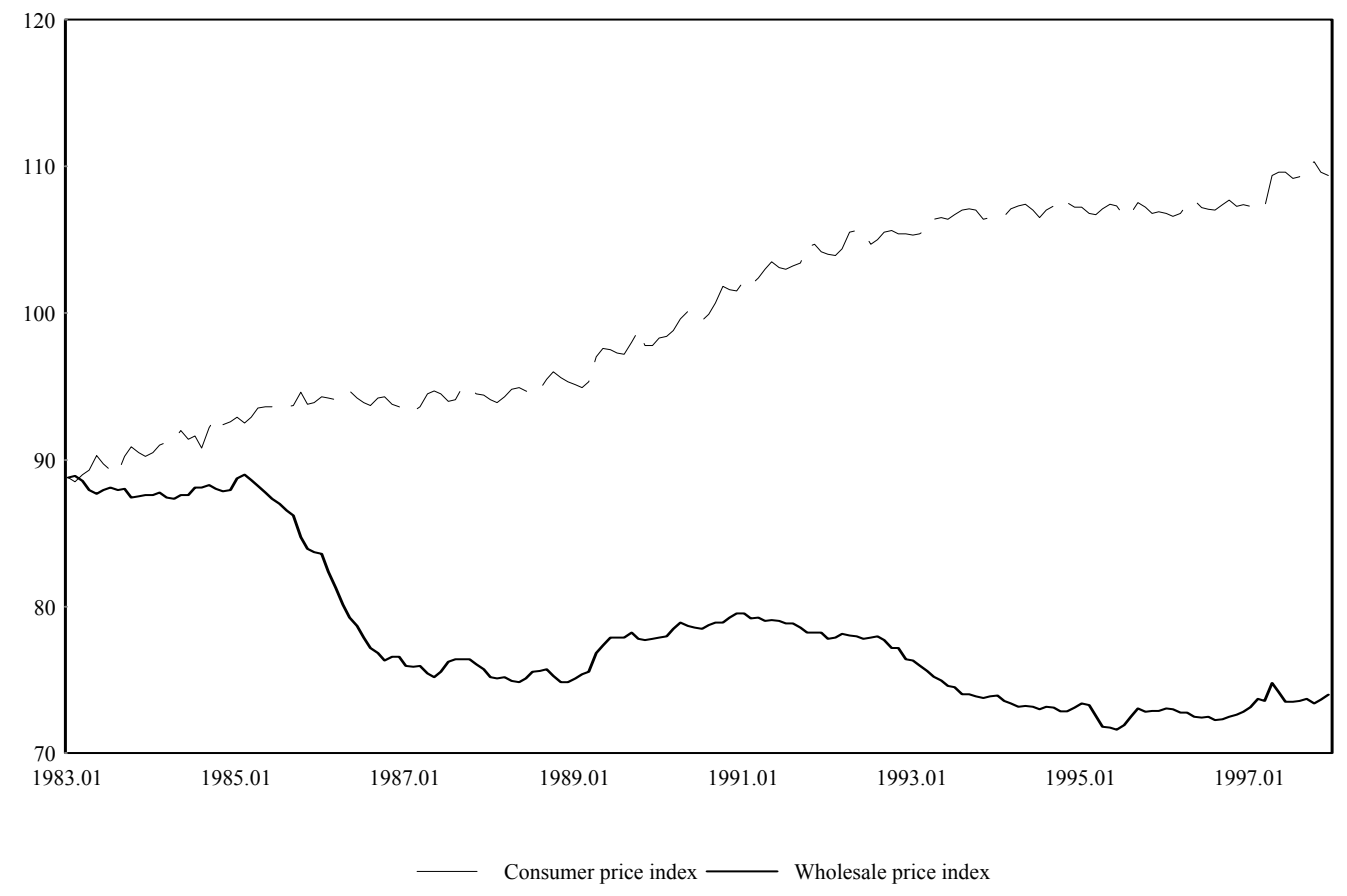


Table 1

Residual diagnostics - Tri-polar System

\begin{tabular}{|c|c|c|c|c|c|}
\hline & Test & Distribution & Test Stat. & $p$-value & \\
\hline & $L M(1)$ & $\chi^{2}(64)$ & 59.888 & 0.620 & \\
\hline & $L M(4)$ & $\chi^{2}(64)$ & 64.757 & 0.450 & \\
\hline & $N M$ & $\chi^{2}(16)$ & 51.167 & 0.000 & \\
\hline & $R^{2}$ & $\mathrm{ARCH}^{\mathrm{a}}$ & Normality $^{\mathrm{b}}$ & Skewness & Kurtosis \\
\hline$s^{\mathrm{GER}}$ & 0.266 & 2.096 & 0.569 & 0.081 & 3.081 \\
\hline$s^{\mathrm{JAP}}$ & 0.267 & 3.441 & 1.798 & -0.233 & 2.894 \\
\hline$p^{\mathrm{GER}}$ & 0.593 & 3.225 & 1.916 & -0.010 & 3.346 \\
\hline$p^{\mathrm{JAP}}$ & 0.600 & 3.151 & $24.346^{c}$ & 0.210 & 5.028 \\
\hline$p^{\mathrm{US}}$ & 0.612 & 3.965 & 3.430 & 0.019 & 3.528 \\
\hline$i^{\mathrm{GER}}$ & 0.443 & 7.305 & $9.222^{\mathrm{c}}$ & -0.224 & 4.059 \\
\hline$i^{\mathrm{JAP}}$ & 0.588 & 0.978 & 2.796 & -0.186 & 3.415 \\
\hline$i^{\mathrm{US}}$ & 0.365 & $13.176^{\mathrm{c}}$ & $9.310^{\mathrm{c}}$ & -0.317 & 4.091 \\
\hline
\end{tabular}

a Test of fourth order ARCH, distributed as $\chi^{2}(4)$.

${ }^{b}$ Normality test, distributed as $\chi^{2}(2)$.

c Significant at five percent level. 
Table 2

Johansen Cointegration Analysis - Tri-polar System

\begin{tabular}{|c|c|c|c|c|}
\hline & Null hypoth. & $\lambda-\max ^{\mathrm{a}}$ & Trace $^{\mathrm{b}}$ & \\
\hline & $r=0$ & $52.34^{\mathrm{c}}$ & $183.00^{c}$ & \\
\hline & $\mathrm{r} \leq 1$ & 40.52 & $130.61^{\mathrm{c}}$ & \\
\hline & $\mathrm{r} \leq 2$ & 27.62 & 90.09 & \\
\hline & $\mathrm{r} \leq 3$ & 23.21 & 62.47 & \\
\hline & $r \leq 4$ & 16.64 & 39.26 & \\
\hline & $\mathrm{r} \leq 5$ & 11.62 & 22.62 & \\
\hline & $r \leq 6$ & 6.96 & 11.01 & \\
\hline & $\mathrm{r} \leq 7$ & 4.05 & 4.05 & \\
\hline & \multicolumn{2}{|c|}{ Standardised Eigenvectors (beta) ${ }^{\mathrm{d}}$} & \multicolumn{2}{|c|}{$\begin{array}{l}\text { Standardised Loadings } \\
\text { (alpha })^{\mathrm{e}}\end{array}$} \\
\hline & Vector 1 & Vector 2 & Vector 1 & Vector 2 \\
\hline$S^{G E R}$ & 1.000 & -0.037 & -0.019 & 0.004 \\
\hline$s^{J A P}$ & -0.625 & 1.000 & -0.010 & 0.010 \\
\hline$p^{G E R}$ & 2.519 & 32.251 & 0.001 & -0.001 \\
\hline$p^{J A P}$ & 2.044 & -19.660 & -0.001 & 0.001 \\
\hline$p^{U S}$ & -1.037 & -21.534 & -0.002 & 0.000 \\
\hline$i^{G E R}$ & 6.091 & -25.298 & -0.458 & 0.019 \\
\hline$i^{J A P}$ & -4.581 & 34.473 & -0.047 & -0.019 \\
\hline$i^{U S}$ & -9.211 & 0.313 & 0.089 & 0.073 \\
\hline
\end{tabular}

${ }^{a}$ The maximum eigenvalue $(\lambda$-max) test for the number of cointegrating vectors.

${ }^{\mathrm{b}}$ The trace test for the number of cointegrating vectors.

${ }^{c}$ Significant at the five percent level, based on critical values taken from Osterwald-Lennum (1992).

d The two most significant vectors arranged by decreasing size of eigenvalue, normalised on the exchange rate term.

${ }^{\mathrm{e}}$ The loadings associated with each vector. 
Table 3

Restrictions on Cointegration Space - Tri-Polar System

\begin{tabular}{lllll}
\hline \hline Hyp. & $\begin{array}{l}\text { Economic } \\
\text { Interpretation }\end{array}$ & Implied Restrictions & Dist. & $\begin{array}{c}\text { Test } \\
\text { Stat. }\end{array}$ \\
\hline A1 & PPP for Germany & $\beta_{1}=(1,0,-1,0,1,0,0,0)^{\prime}$ & $\chi^{2}(6)$ & $30.81^{\mathrm{a}}$ \\
A2 & PPP for Japan & $\beta_{2}=(0,1,0,-1,1,0,0,0)^{\prime}$ & $\chi^{2}(6)$ & $31.38^{\mathrm{a}}$ \\
A3 & PPP holds for both & $\beta_{1}=(1,0,-1,0,1,0,0,0)^{\prime}$ & $\chi^{2}(12)$ & $73.22^{\mathrm{a}}$ \\
& & $\beta_{2}=(0,1,0,-1,1,0,0,0)^{\prime}$ & & \\
B1 & PPP plus interest & $\beta_{1}=(1,0,-1,0,1, m, 0,-m)^{\prime}$ & $\chi^{2}(5)$ & 3.55 \\
& differential for Germany & & \\
B2 & $\begin{array}{l}\text { PPP plus interest } \\
\text { differential for Japan }\end{array}$ & $\beta_{2}=(0,1,0,-1,1,0, n,-n)^{\prime}$ & $\chi^{2}(5)$ & 8.79 \\
& $\begin{array}{l}\text { PPP plus interest } \\
\text { B3 }\end{array}$ & $\beta_{1}=(1,0,-1,0,1, m, 0,-m)^{\prime}$ & $\chi^{2}(10)$ & 16.80 \\
& differentials for both & $\beta_{2}=(0,1,0,-1,1,0, n,-n)^{\prime}$ & & \\
\hline \hline
\end{tabular}

Significant at the five percent level. 
Table 4

Loadings of Cointegrating Vectors

\begin{tabular}{lcc}
\hline \hline Variable & $\mathrm{CV}_{1}^{\mathrm{a}}$ & $\mathrm{CV}_{2}$ \\
\hline$s^{G E R}$ & -0.017 & -0.006 \\
& $(1.05)$ & $(0.67)$ \\
& & \\
$s^{J A P}$ & 0.007 & -0.022 \\
& $(0.49)$ & $(2.84)$ \\
$p^{G E R}$ & 0.002 & -0.000 \\
& $(2.54)$ & $(0.52)$ \\
$p^{J A P}$ & 0.000 & -0.002 \\
& $(0.19)$ & $(1.97)$ \\
$p^{U S}$ & -0.001 & 0.001 \\
& $(1.52)$ & $(1.62)$ \\
$i^{G E R}$ & -0.490 & 0.151 \\
& $(4.64)$ & $(2.83)$ \\
$i^{J A P}$ & 0.092 & -0.075 \\
& $(1.05)$ & $(1.70)$ \\
$i^{U S}$ & 0.039 & -0.044 \\
& $(0.27)$ & $(0.61)$ \\
\hline \hline
\end{tabular}

a $t$-statistics in parentheses. 


\section{Figure 4}

Generalised impulse responses to an (historic) innovation in US Prices ( - impulse responses, -- cumulated impulse responses)
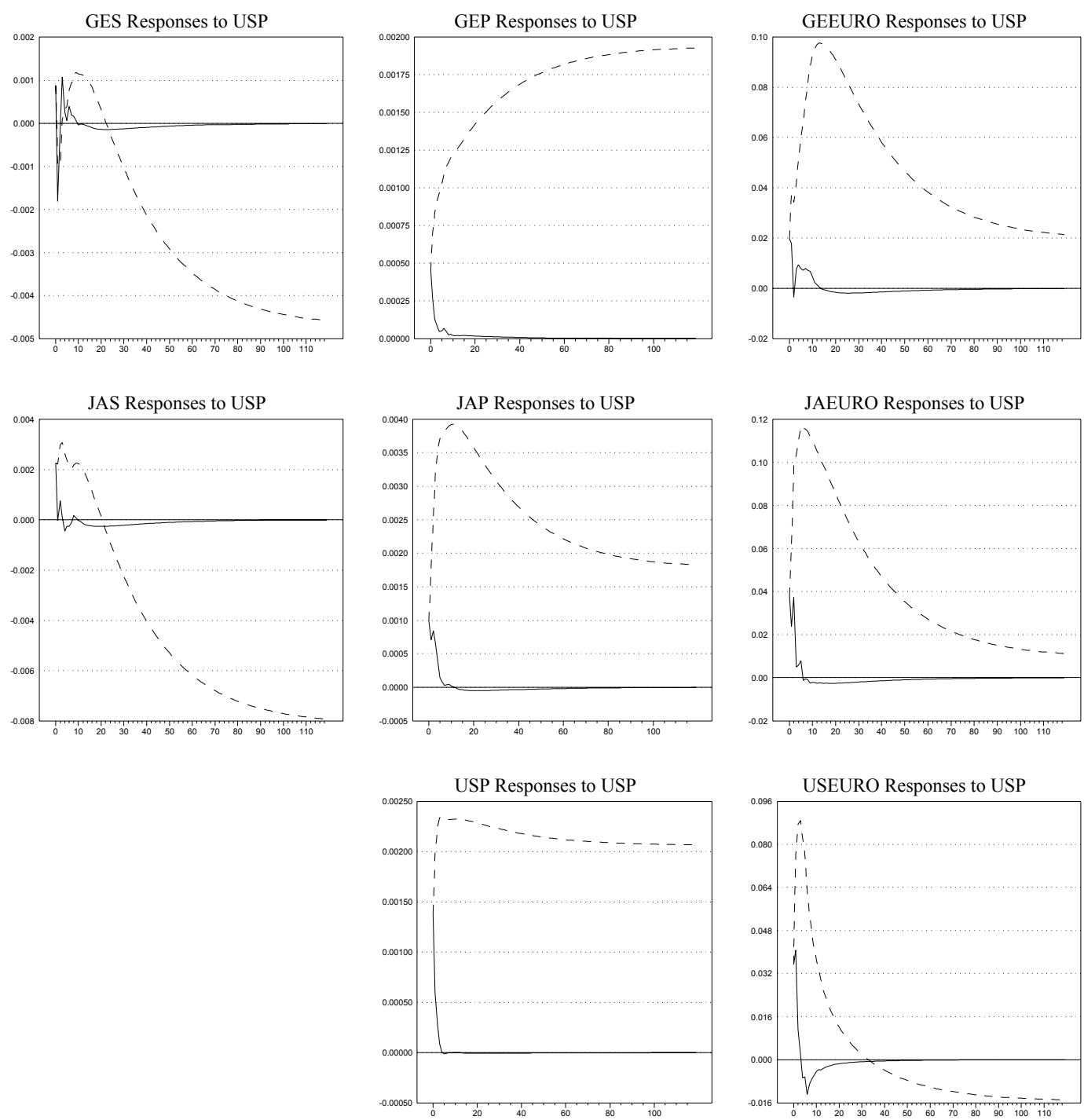


\section{Figure 5}

Generalised impulse responses to an (historic) innovation in German prices ( - impulse responses, - - cumulated impulse responses)
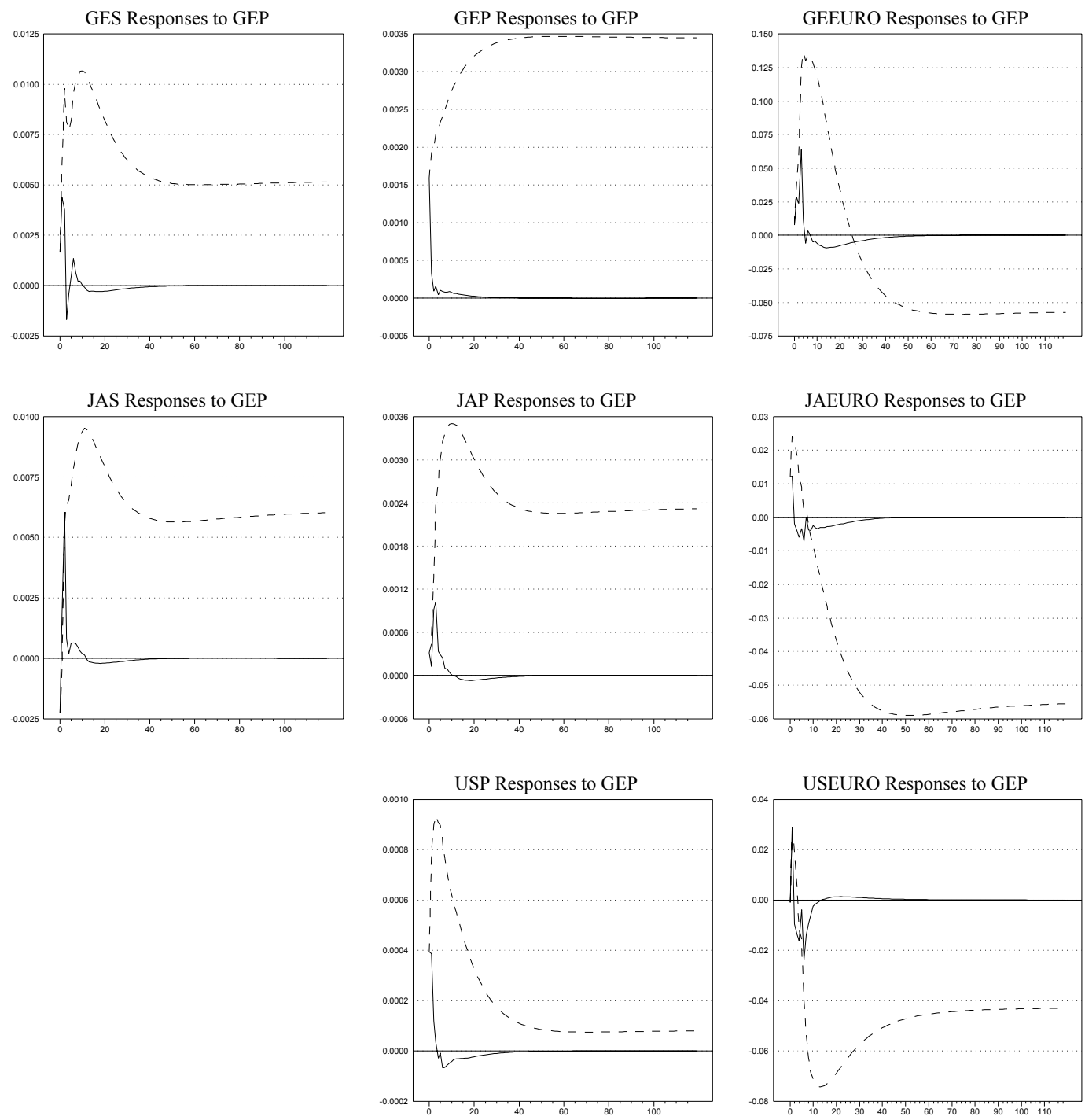
Figure 6

Generalised impulse responses to an (historic) innovation in Japanese interest rates ( - impulse responses, -- cumulated impulse responses)
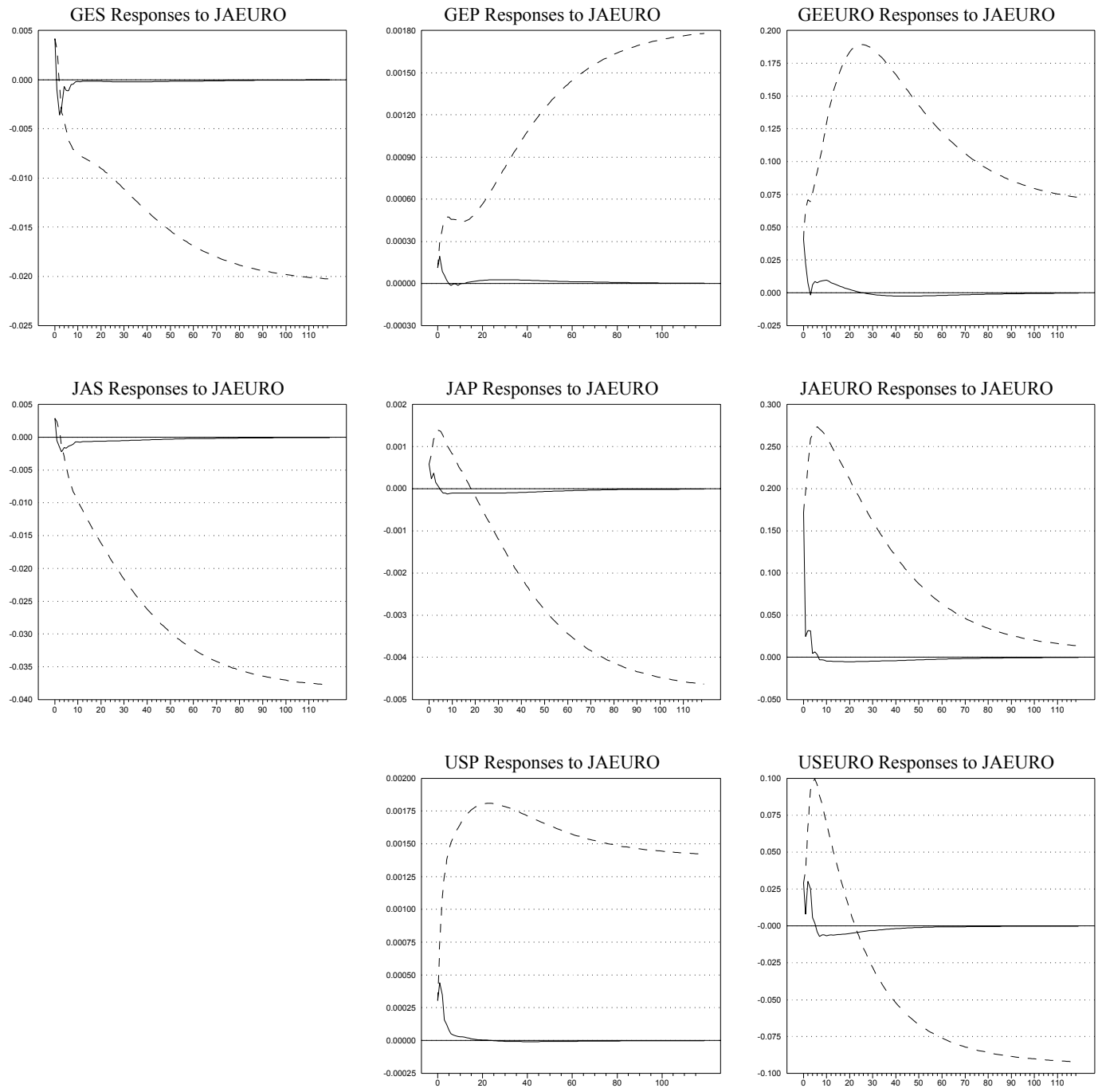
Figure 7

Generalised impulse responses of error correction terms to an (historic) innovation in Japanese interest rates)
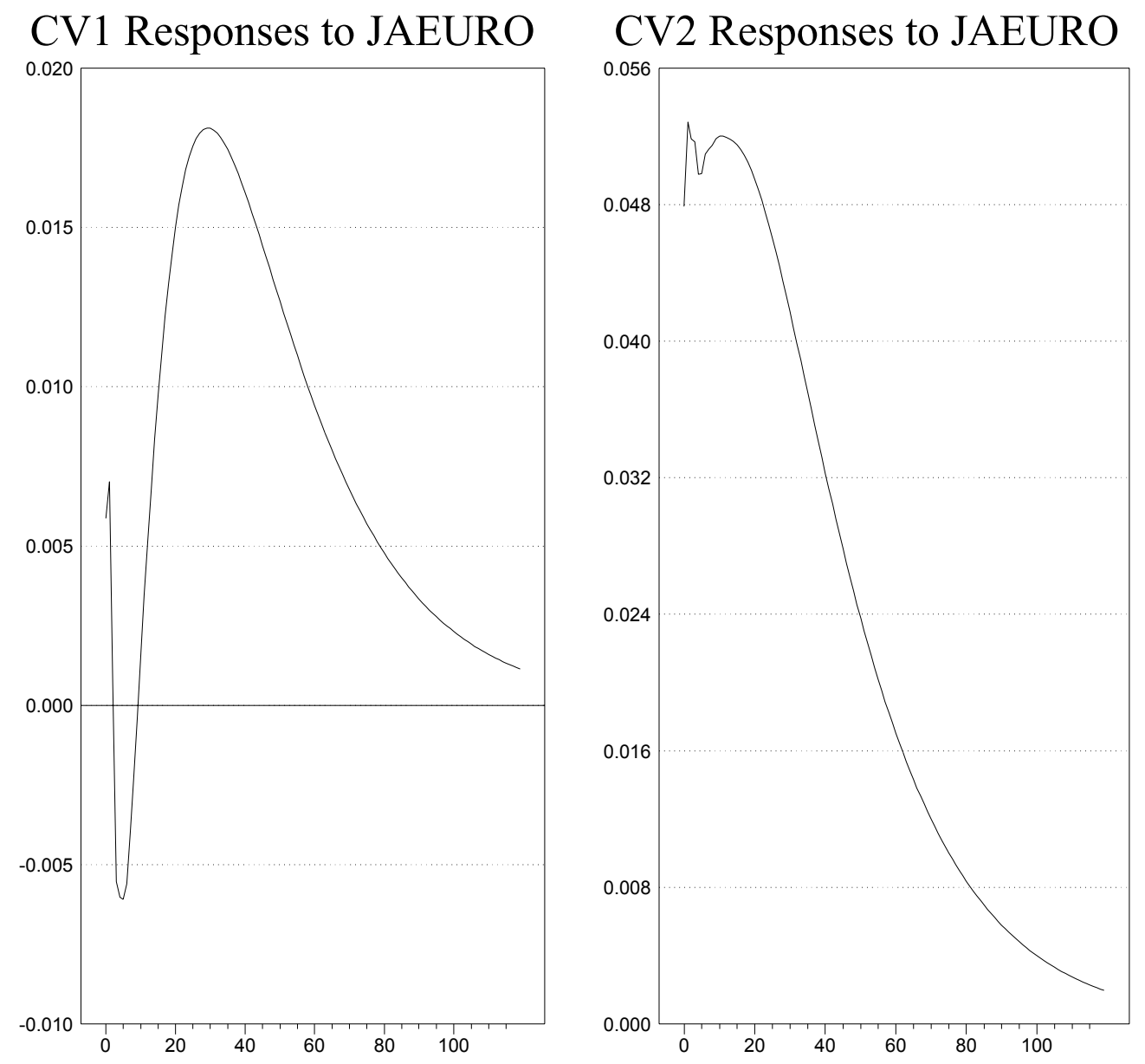
Figure 8

Cointegrating relationships - time-variation in parameters

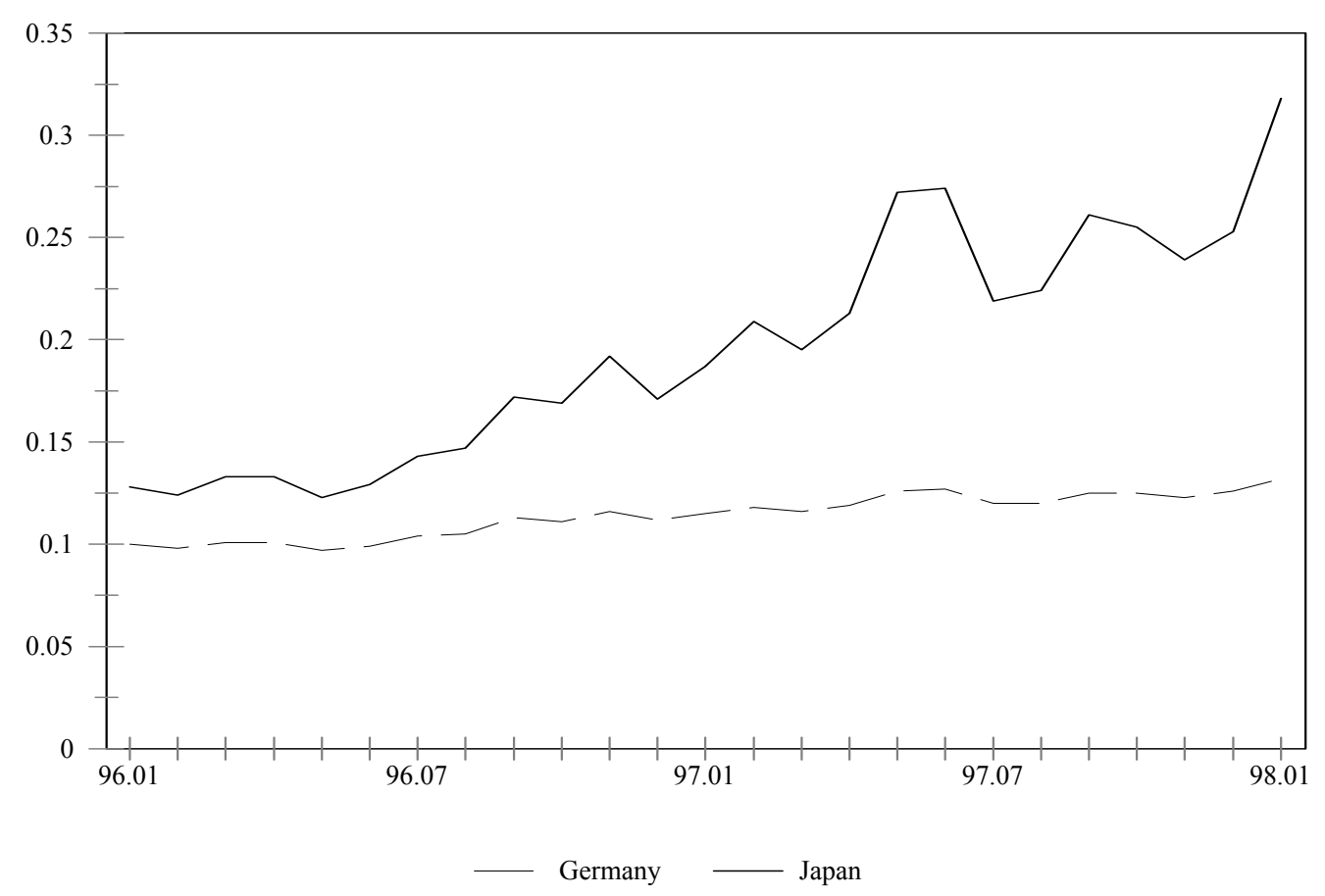


Table 5

Forecast performance - Tri-polar model

\begin{tabular}{lcccccc}
\hline \hline Horizon & \multicolumn{3}{c}{ Deutschemark } & \multicolumn{3}{c}{ Japanese Yen } \\
\hline $\begin{array}{c}\text { RMSE } \\
\text { Ratio } \\
\text { (Model) }\end{array}$ & Direction & $\begin{array}{c}\text { RMSE } \\
\text { Ratio } \\
\text { (VAR) }\end{array}$ & $\begin{array}{c}\text { RMSE } \\
\text { Ratio } \\
(\text { Model) }\end{array}$ & Direction & $\begin{array}{c}\text { RMSE } \\
\text { Ratio } \\
\text { (VAR) }\end{array}$ \\
\cline { 2 - 6 } 1 & 0.966 & 56.0 & 1.040 & 1.112 & 44.0 & 1.141 \\
2 & 0.957 & 68.0 & 1.111 & 1.058 & 68.0 & 1.244 \\
3 & 0.985 & 56.0 & 1.198 & $0.899^{\mathrm{b}}$ & 80.0 & 1.317 \\
4 & 0.942 & 64.0 & 1.245 & $0.799^{\mathrm{a}}$ & 80.0 & 1.381 \\
5 & $0.901^{\mathrm{a}}$ & 62.5 & 1.280 & $0.758^{\mathrm{b}}$ & 79.2 & 1.401 \\
6 & $0.896^{\mathrm{b}}$ & 65.2 & 1.316 & $0.730^{\mathrm{c}}$ & 78.3 & 1.458 \\
7 & $0.886^{\mathrm{b}}$ & 63.6 & 1.320 & $0.646^{\mathrm{c}}$ & 90.9 & 1.545 \\
8 & $0.911^{\mathrm{a}}$ & 57.1 & 1.335 & $0.587^{\mathrm{c}}$ & 95.2 & 1.610 \\
9 & $0.916^{\mathrm{c}}$ & 65.0 & 1.344 & $0.607^{\mathrm{c}}$ & 100.0 & 1.641 \\
10 & $0.895^{\mathrm{c}}$ & 78.9 & 1.355 & $0.619^{\mathrm{c}}$ & 94.7 & 1.651 \\
11 & $0.896^{\mathrm{c}}$ & 77.8 & 1.358 & $0.587^{\mathrm{c}}$ & 100.0 & 1.643 \\
12 & $0.900^{\mathrm{c}}$ & 88.2 & 1.357 & $0.583^{\mathrm{c}}$ & 100.0 & 1.622 \\
\hline \hline
\end{tabular}

${ }^{\text {a }}$ Significantly superior performance by the tri-polar model compared to the random walk alternative at the ten percent level in a one-tailed test.

${ }^{\mathrm{b}}$ Significantly superior performance by the tri-polar model compared to the random walk alternative at the five percent level in a one-tailed test.

${ }^{c}$ Significantly superior performance by the tri-polar model compared to the random walk alternative at the one percent level in a one-tailed test. 
Figure A1
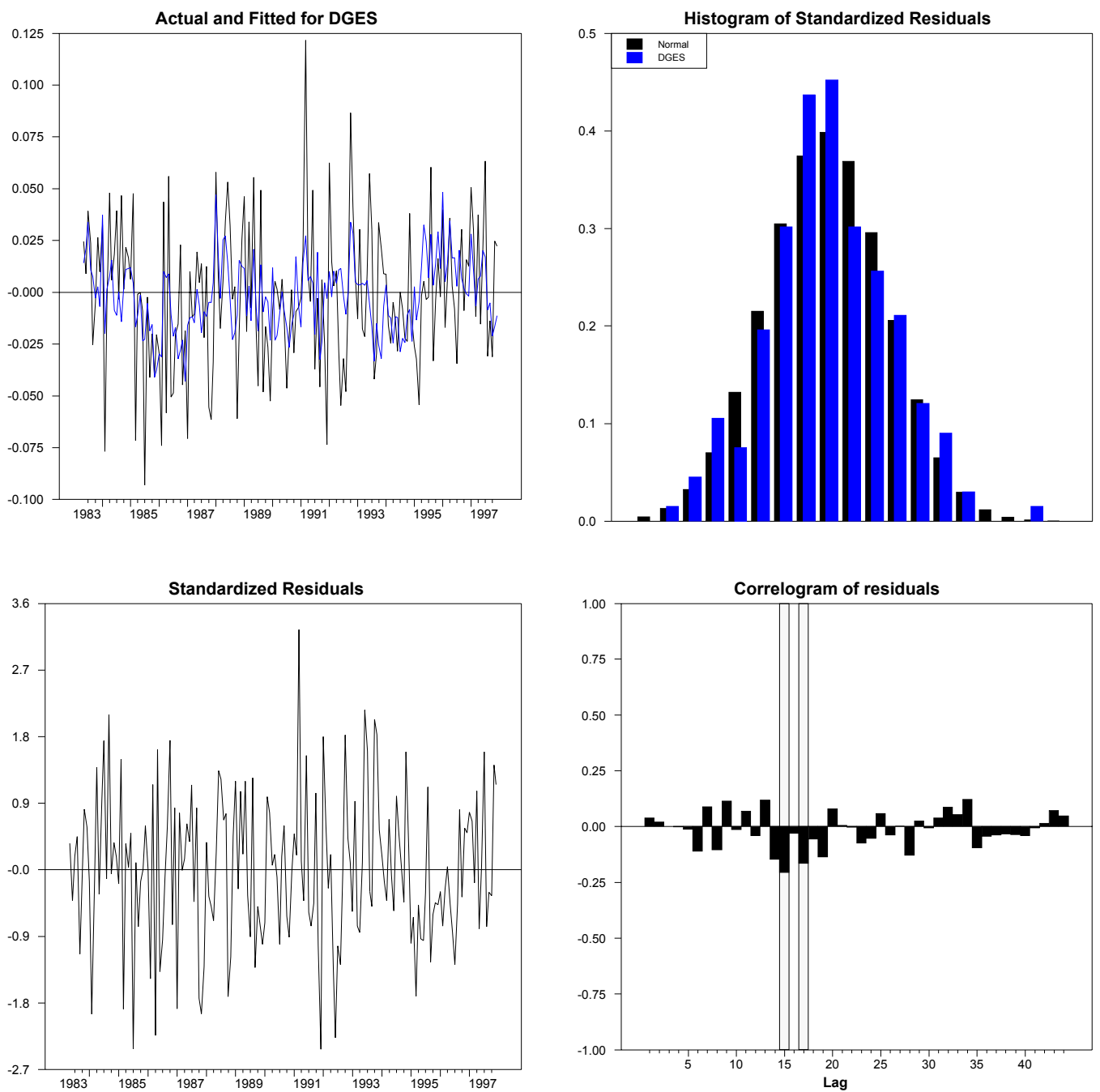
Figure A2
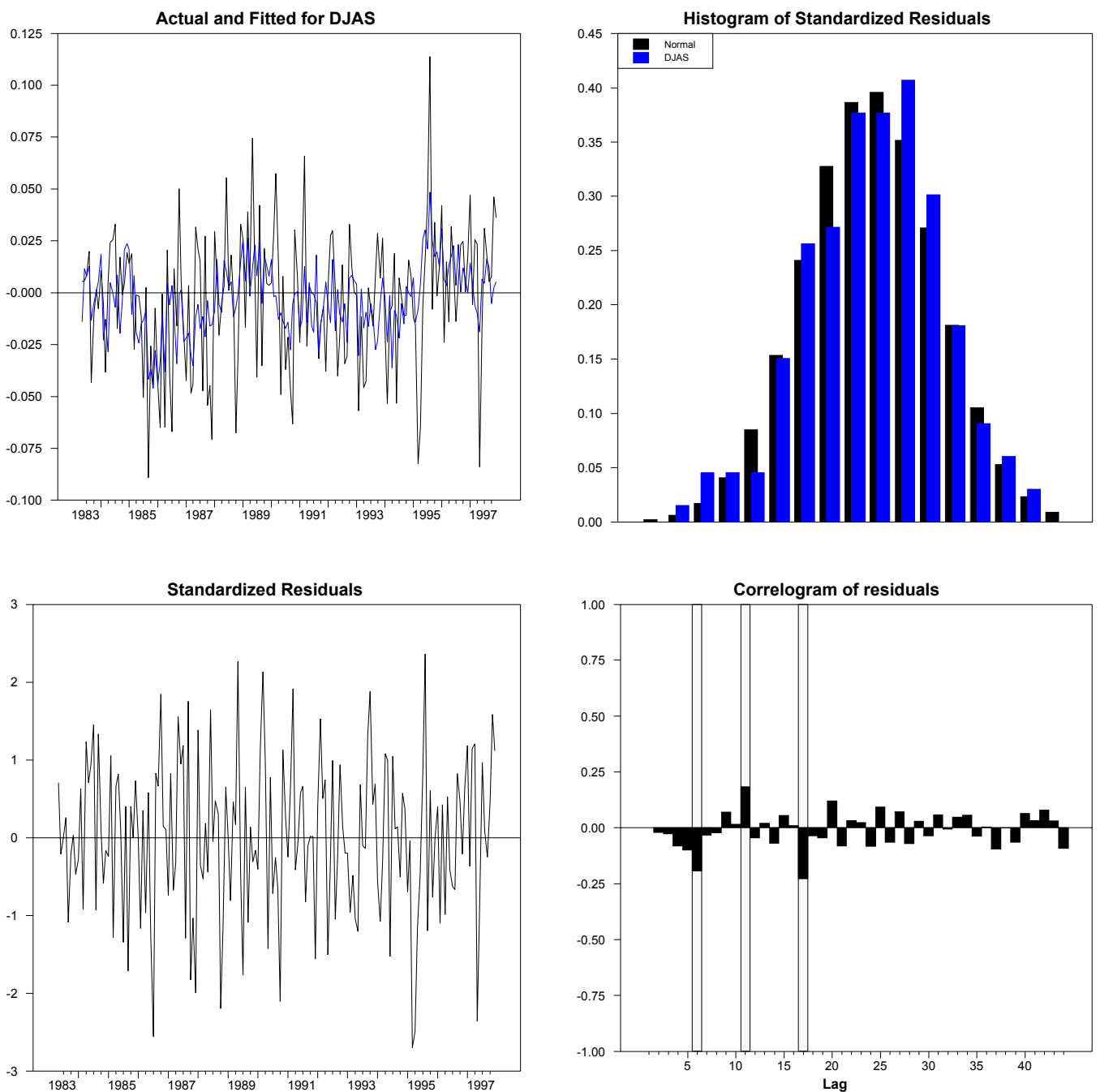
Figure A3
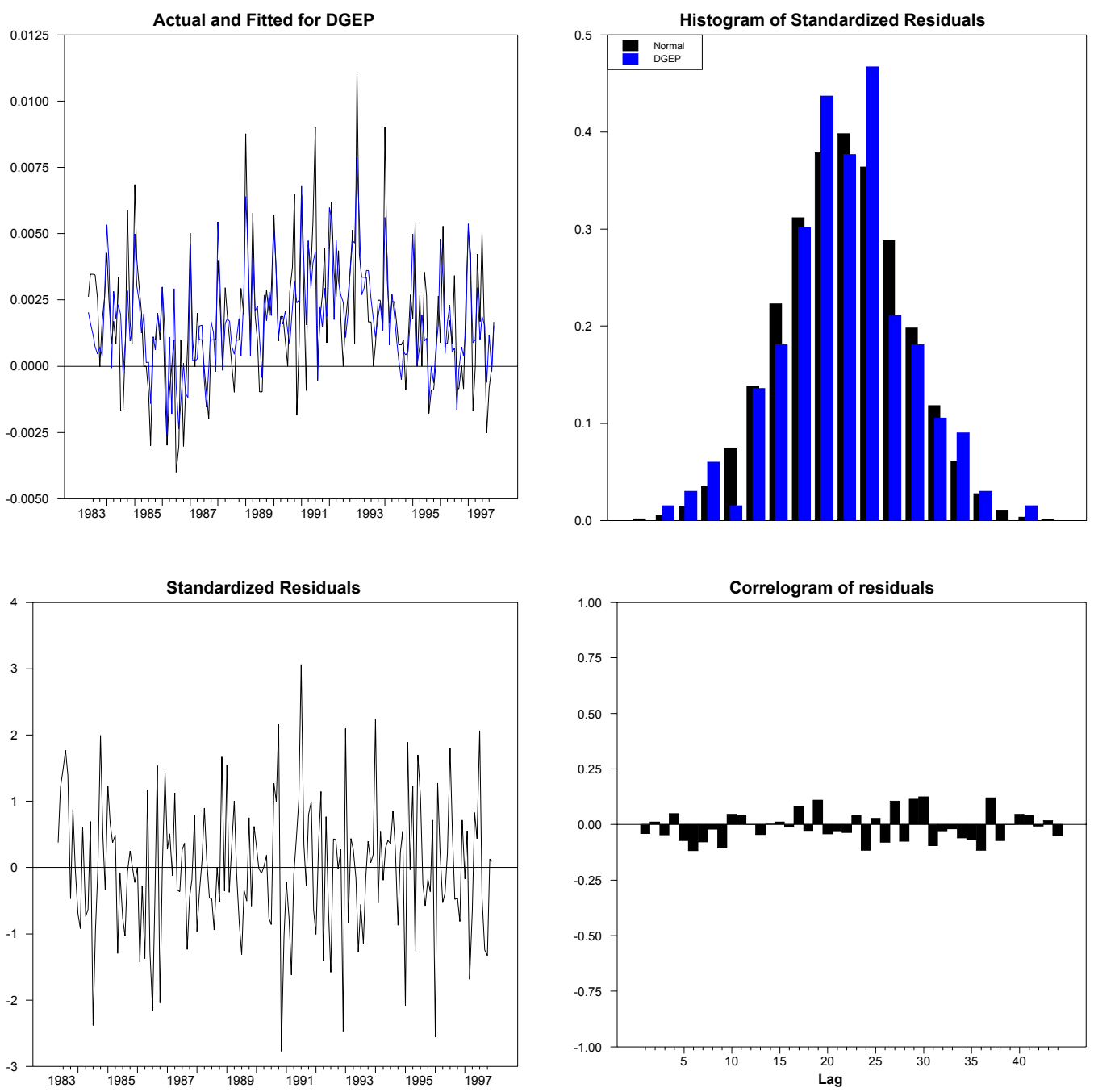
Figure A4
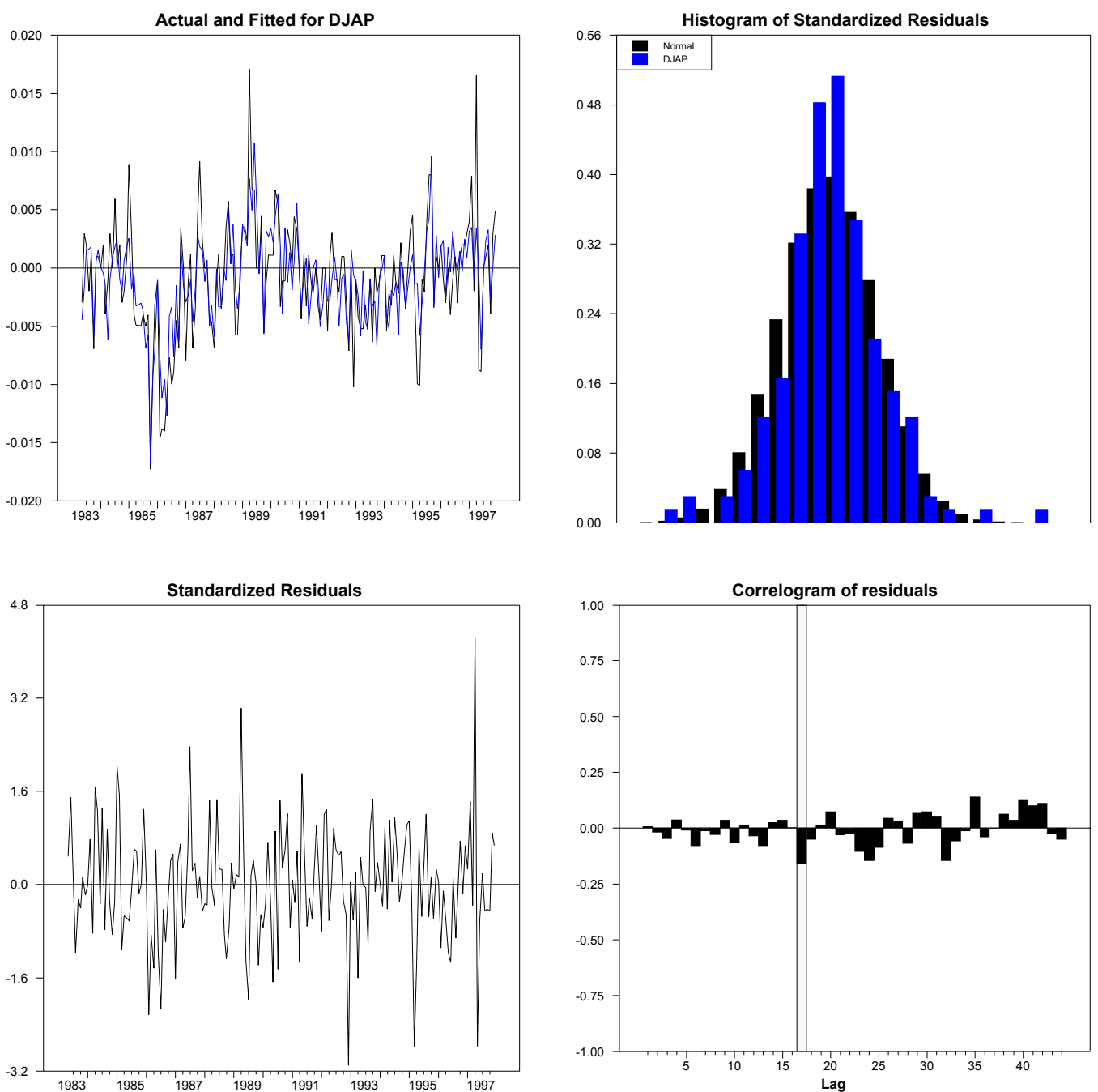
Figure A5
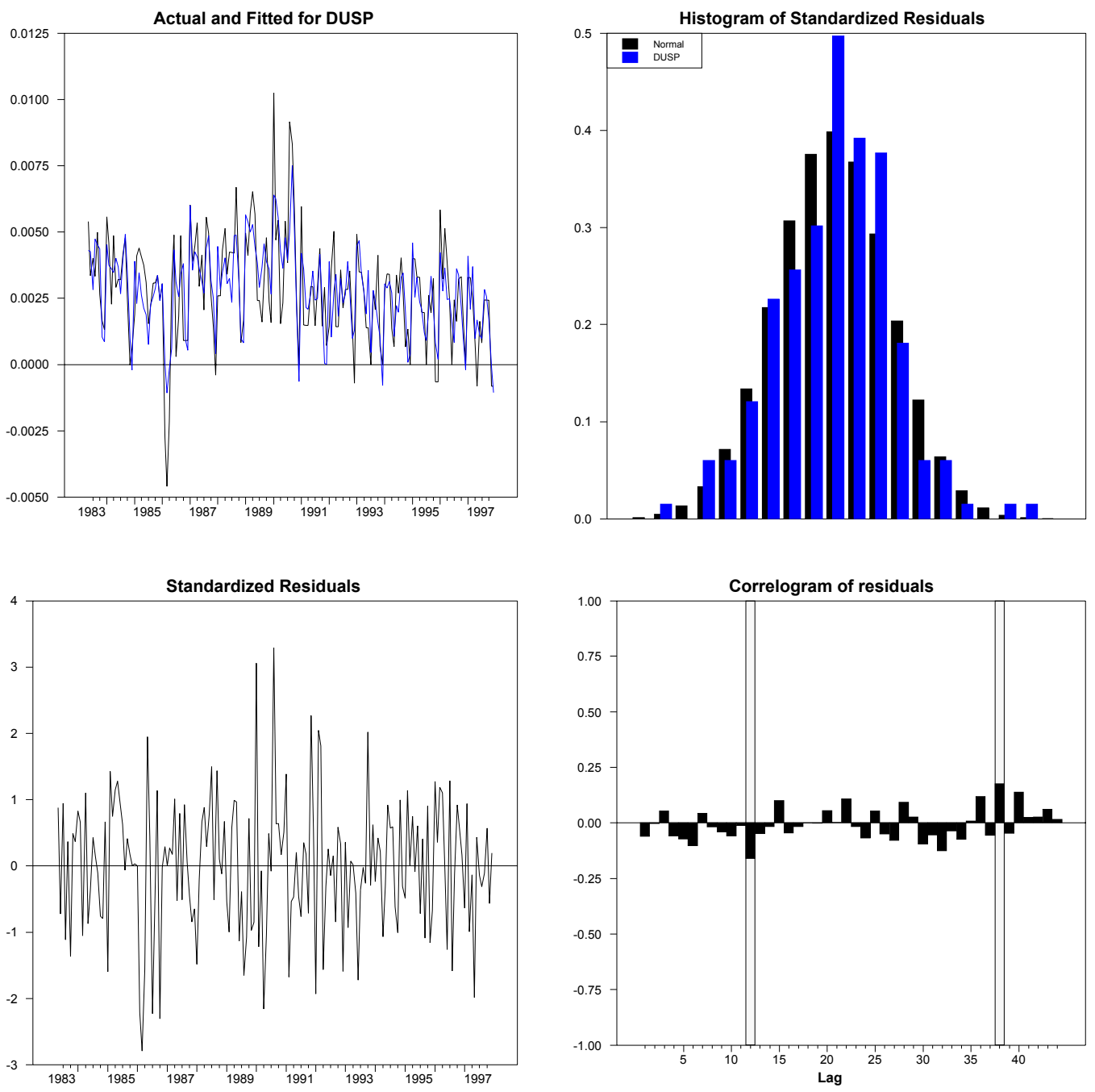
Figure A6
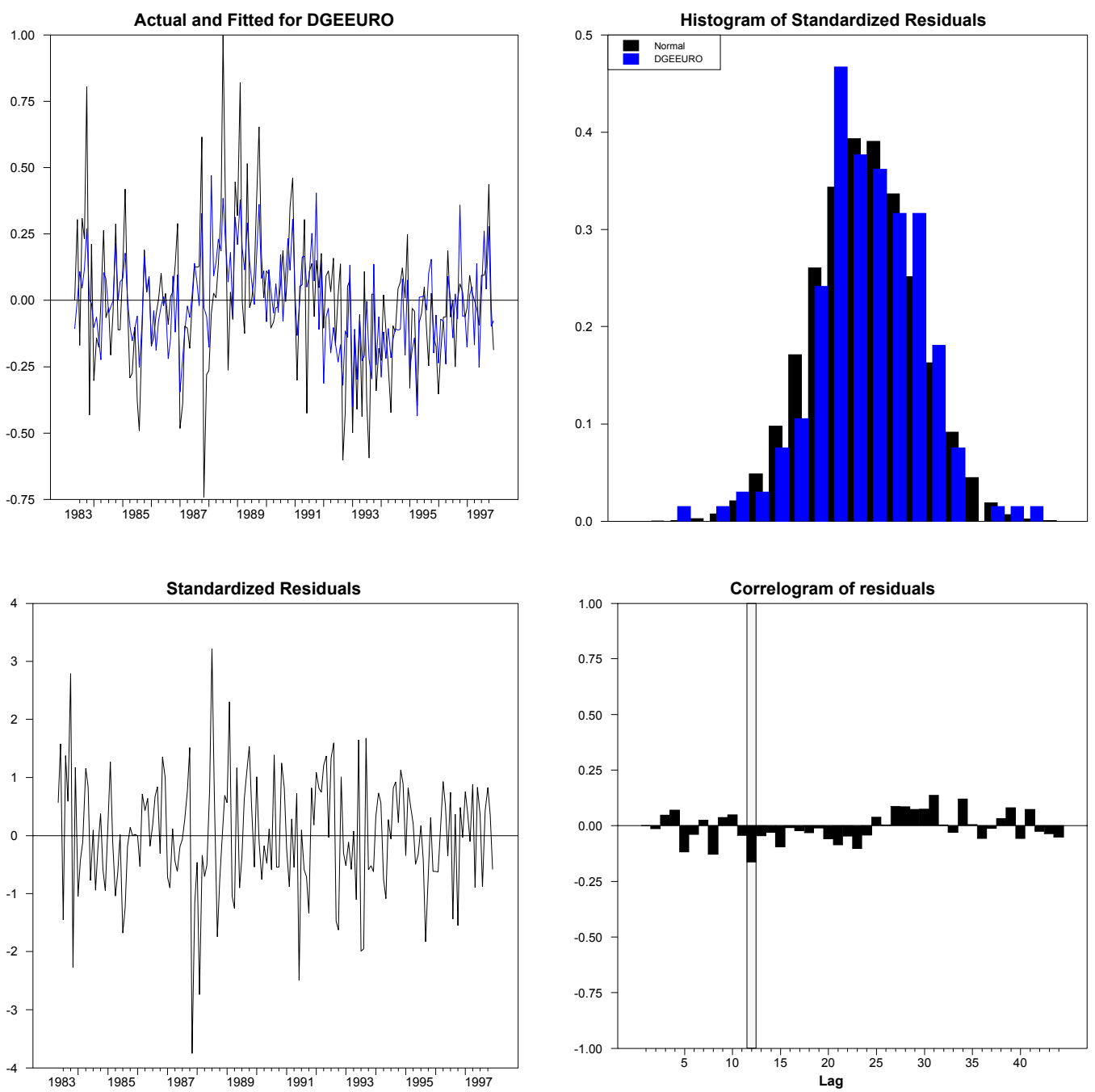
Figure A7
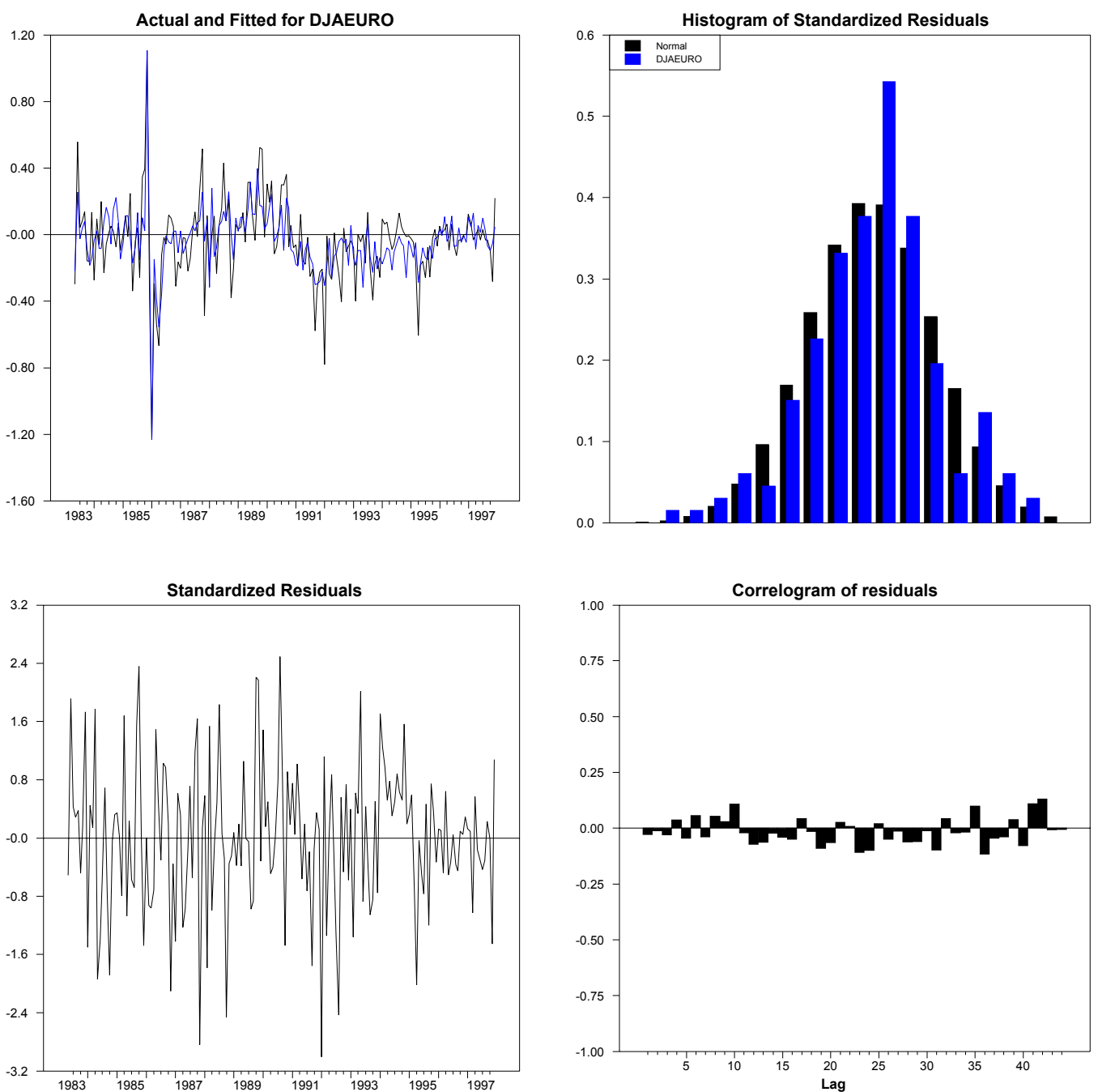
Figure A8
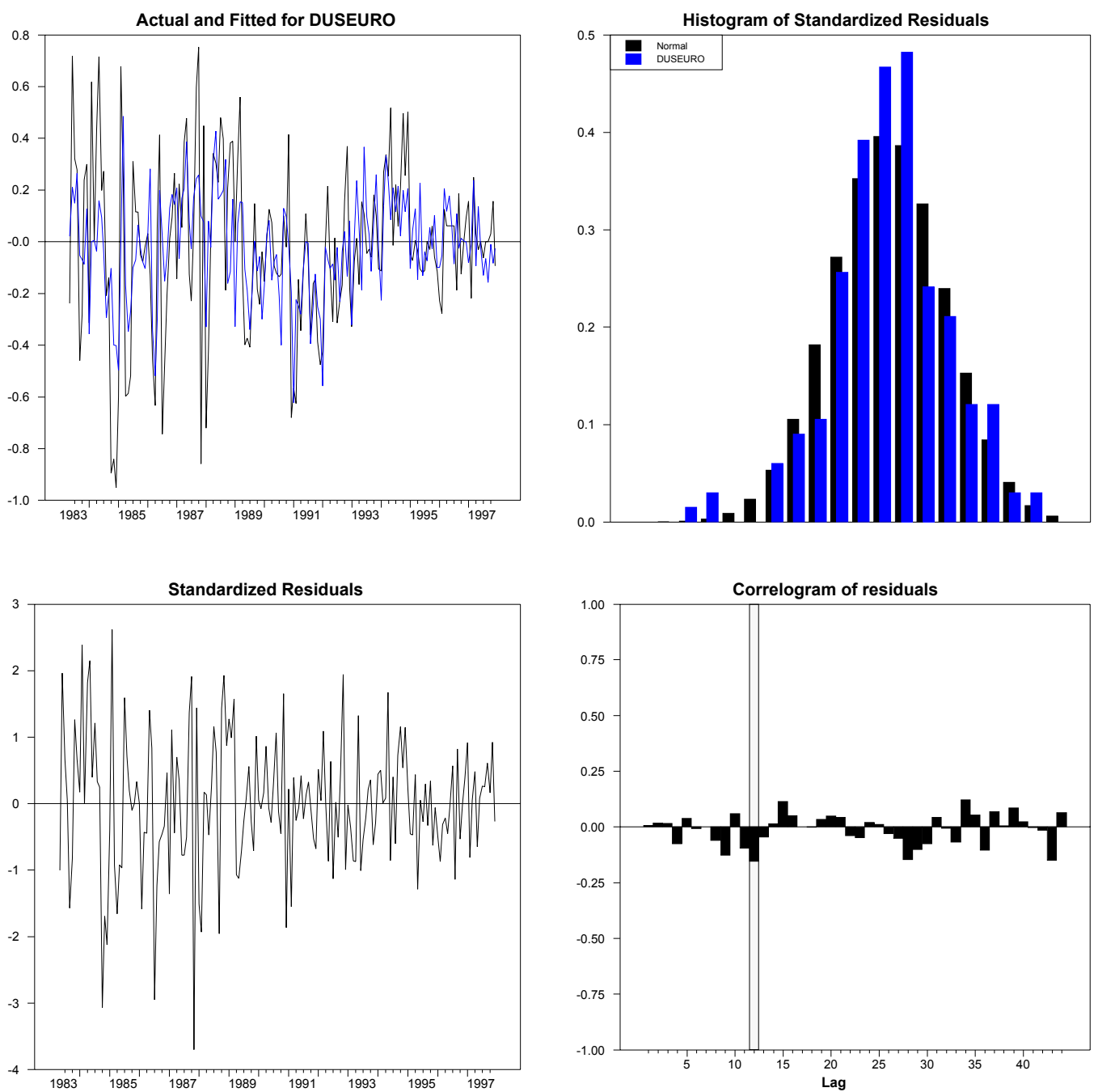
Figure A9
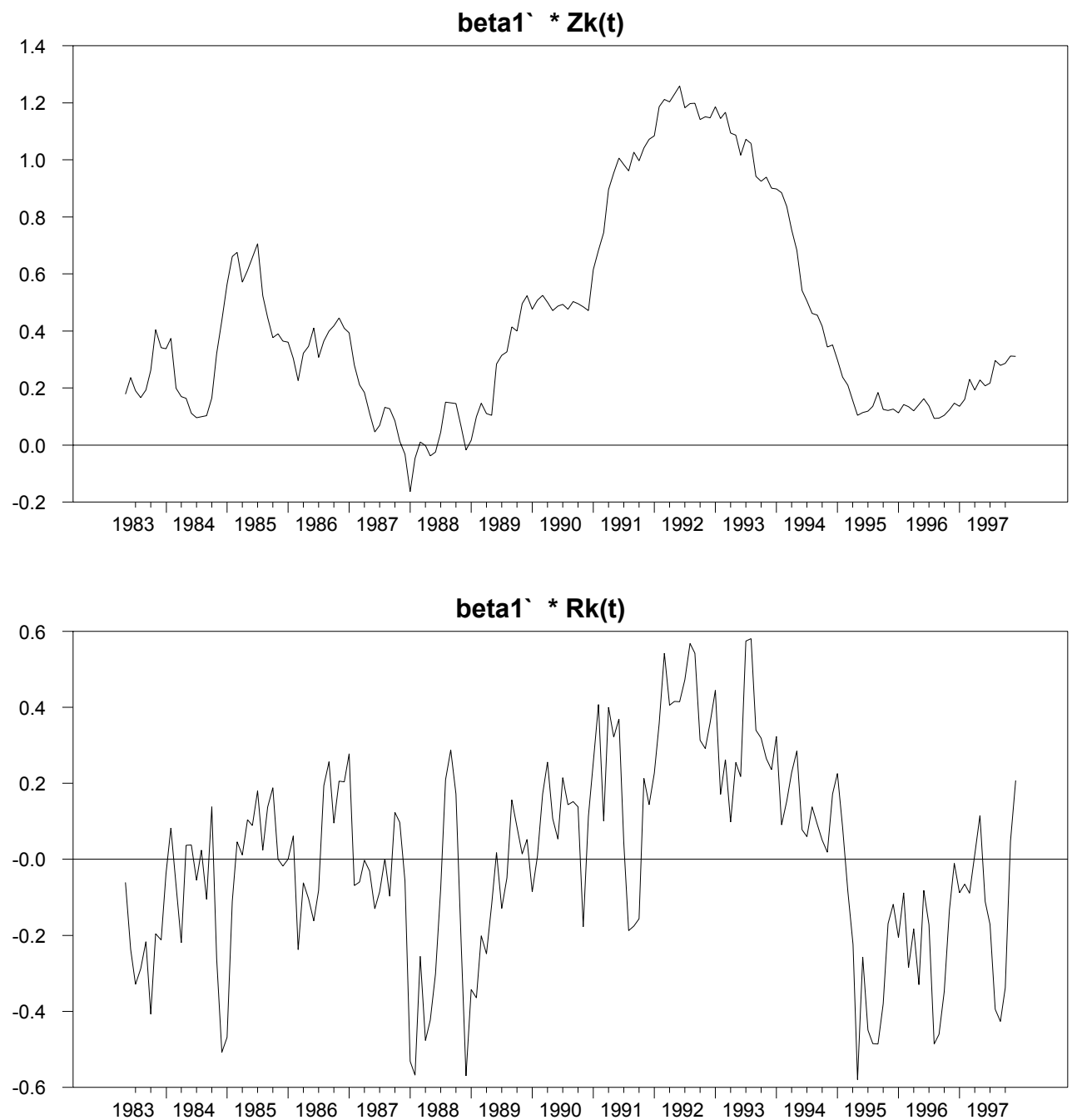
Figure A10
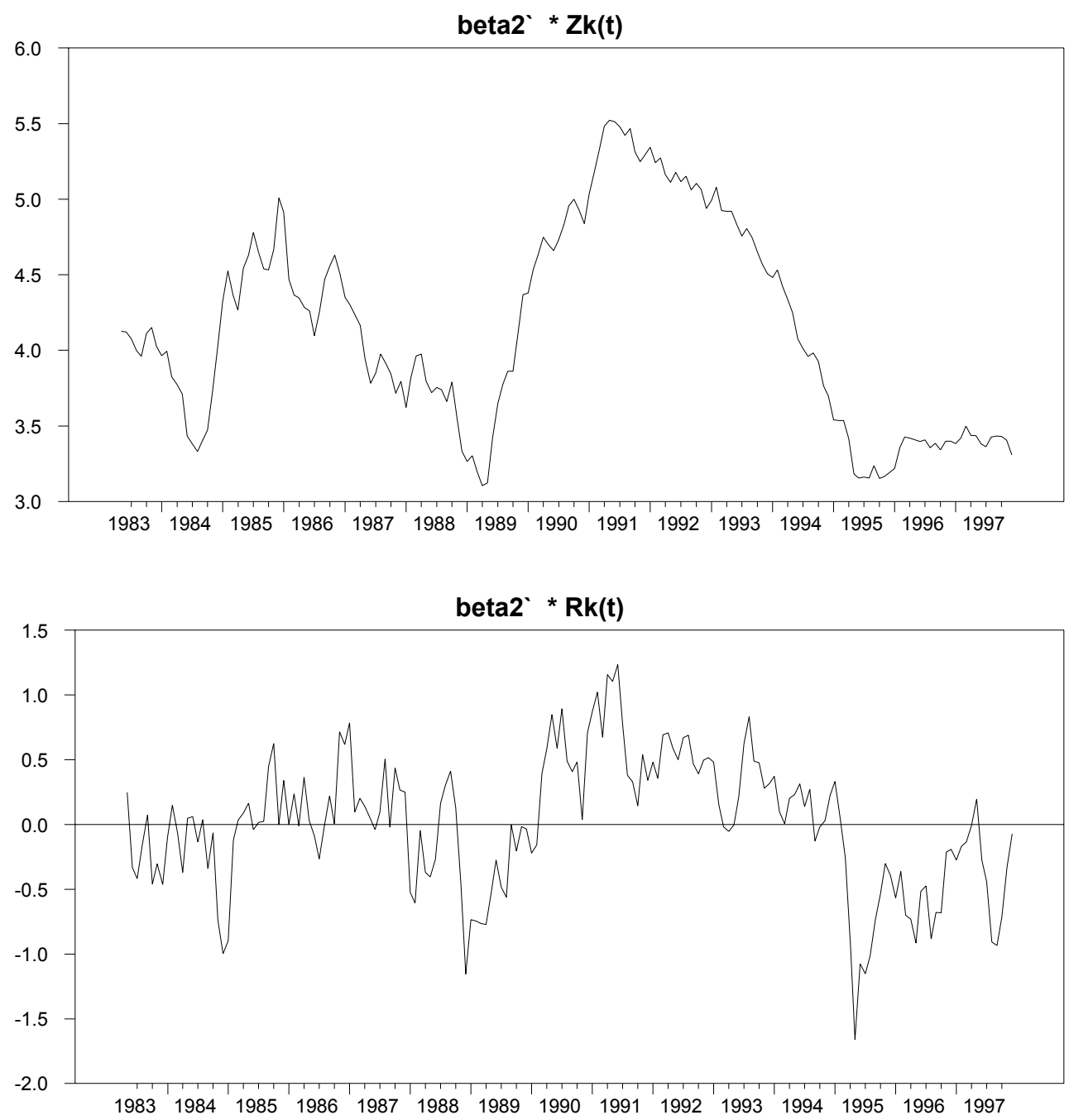
Figure A11






\section{List of other working papers:}

1999

1. Yin-Wong Cheung, Menzie Chinn and Ian Marsh, How do UK-Based Foreign Exchange Dealers Think Their Market Operates?, WP99-21

2. Soosung Hwang, John Knight and Stephen Satchell, Forecasting Volatility using LINEX Loss Functions, WP99-20

3. Soosung Hwang and Steve Satchell, Improved Testing for the Efficiency of Asset Pricing Theories in Linear Factor Models, WP99-19

4. Soosung Hwang and Stephen Satchell, The Disappearance of Style in the US Equity Market, WP99-18

5. Soosung Hwang and Stephen Satchell, Modelling Emerging Market Risk Premia Using Higher Moments, WP99-17

6. Soosung Hwang and Stephen Satchell, Market Risk and the Concept of Fundamental Volatility: Measuring Volatility Across Asset and Derivative Markets and Testing for the Impact of Derivatives Markets on Financial Markets, WP99-16

7. Soosung Hwang, The Effects of Systematic Sampling and Temporal Aggregation on Discrete Time Long Memory Processes and their Finite Sample Properties, WP99-15

8. Ronald MacDonald and Ian Marsh, Currency Spillovers and Tri-Polarity: a Simultaneous Model of the US Dollar, German Mark and Japanese Yen, WP99-14

9. Robert Hillman, Forecasting Inflation with a Non-linear Output Gap Model, WP99-13

10. Robert Hillman and Mark Salmon, From Market Micro-structure to Macro Fundamentals: is there Predictability in the Dollar-Deutsche Mark Exchange Rate?, WP99-12

11. Renzo Avesani, Giampiero Gallo and Mark Salmon, On the Evolution of Credibility and Flexible Exchange Rate Target Zones, WP99-11

12. Paul Marriott and Mark Salmon, An Introduction to Differential Geometry in Econometrics, WP99-10

13. Mark Dixon, Anthony Ledford and Paul Marriott, Finite Sample Inference for Extreme Value Distributions, WP99-09

14. Ian Marsh and David Power, A Panel-Based Investigation into the Relationship Between Stock Prices and Dividends, WP99-08

15. Ian Marsh, An Analysis of the Performance of European Foreign Exchange Forecasters, WP99-07

16. Frank Critchley, Paul Marriott and Mark Salmon, An Elementary Account of Amari's Expected Geometry, WP99-06

17. Demos Tambakis and Anne-Sophie Van Royen, Bootstrap Predictability of Daily Exchange Rates in ARMA Models, WP99-05

18. Christopher Neely and Paul Weller, Technical Analysis and Central Bank Intervention, WP9904

19. Christopher Neely and Paul Weller, Predictability in International Asset Returns: A Reexamination, WP99-03

20. Christopher Neely and Paul Weller, Intraday Technical Trading in the Foreign Exchange Market, WP99-02

21. Anthony Hall, Soosung Hwang and Stephen Satchell, Using Bayesian Variable Selection Methods to Choose Style Factors in Global Stock Return Models, WP99-01

\section{8}

1. Soosung Hwang and Stephen Satchell, Implied Volatility Forecasting: A Compaison of Different Procedures Including Fractionally Integrated Models with Applications to UK Equity Options, WP98-05

2. Roy Batchelor and David Peel, Rationality Testing under Asymmetric Loss, WP98-04

3. Roy Batchelor, Forecasting T-Bill Yields: Accuracy versus Profitability, WP98-03 
4. Adam Kurpiel and Thierry Roncalli, Option Hedging with Stochastic Volatility, WP98-02

5. Adam Kurpiel and Thierry Roncalli, Hopscotch Methods for Two State Financial Models, WP98-01 